\title{
Author Query
}

AQ1 Please supply all author names. 


\title{
17
}

\section{Ultrasound Effects on Processes and Reactions Involving Carbohydrates}

\author{
A.C. Soria ${ }^{1}$, M. Villamiel ${ }^{2}$, and A. Montilla ${ }^{2}$ \\ ${ }^{1}$ Instituto de Química Orgánica General (CSIC), Juan de la Cierva 3, 28006-Madrid, Spain \\ ${ }^{2}$ Instituto de Investigación en Ciencias de la Alimentación, CIAL (CSIC-UAM), Nicolás Cabrera 9, \\ E-28049, Madrid, Spain
}

17.1 Introduction

$\begin{array}{llr}17.2 & \text { Sonophysical Effects } & 439\end{array}$

17.2.1 Depolymerization 439

17.2.2 Effects of Ultrasound on Functional Properties of Carbohydrates 441

17.2.2.1 Technological Properties 441

17.2.2.2 Bioactive Properties 443

17.2.3 Use of Ultrasound in Carbohydrate Chemistry 443

17.2.3.1 Acylation 443

17.2.3.2 Esterification 443

17.2.3.3 Oligomerization 444

17.2.3.4 Oxidation 444

17.2.3.5 Isomerization 444

17.2.4 Crystallization $\quad 444$

17.3 Sonochemical Effects on Carbohydrate Depolymerization 446

17.4 Effects of Ultrasound on Biotechnological Processes 448

17.4.1 Depolymerization $\quad 449$

17.4.1.1 Simultaneous Application $\quad 450$

17.4.1.2 Sequential Application $\quad 451$

Ultrasound in Food Processing: Recent Advances, First Edition. Edited by Mar Villamiel.

(C) 2017 John Wiley \& Sons, Ltd. Published 2017 by John Wiley \& Sons, Ltd. 
17.4.2 Other Bioprocesses 453

17.4.2.1 Hydrolysis 453

17.4.2.2 Enzymatic Synthesis of Carbohydrate Derivatives $\quad 454$

17.4.2.3 Fermentation 455

17.5 Conclusions and Future Trends 457

Acknowledgements 458

References $\quad 458$

\subsection{Introduction}

Carbohydrates are the most profuse and diverse kind of organic compounds occurring in nature. In organisms they can act as energy reserves, structural materials, protective substances, cell recognition moieties, and information transfer agents. Carbohydrates are also one of the most important components of foods; they can be either naturally present or deliberately added to improve the palatability and overall quality of a food product.

Because of their structural heterogeneity, it is not surprising that carbohydraterelated compounds have been shown to play an important role in the development of new products. In general, carbohydrates with low molecular weights $\left(M_{\mathrm{w}}\right)$ are responsible for the characteristic organoleptic properties in food, but the increase in $M_{\mathrm{w}}$ and the inclusion of certain functional groups can confer to the glycosidic structure a wide range of technological properties, such as viscosity, gelling, thickening, emulsification, and formation of edible films. Moreover, biological activities related to the improvement of metabolic function, decrease in blood lipid levels, control of cardiovascular disease, and prebiotic effect, among other properties, have placed some carbohydrates in a privileged place of interest for current investigations.

During food processing, structural modifications affecting carbohydrates or formation of derivatives as a consequence of carbohydrate interaction with other food constituents can also take place (e.g. caramelization, Maillard reaction, etc.). In addition, with the aim of broadening the applicability of carbohydrates in the elaboration of foods or to obtain bioactive oligosaccharides, some changes can also be deliberately produced by different techniques. In this regard, ultrasound (US) has emerged as a tool of interest for different applications, including polysaccharide depolymerization, which can result in the modification of functional properties of the carbohydrates obtained, synthesis of carbohydrate derivatives by sonophysical effects or by enzymatic processes assisted by US, crystallization, etc. (Mason et al., 1996; Kardos and Luche, 2001; Bhaskaracharya et al., 2009; Kwiatkowska et al., 2011; Deora et al., 2013; Chatel et al., 2014).

Broadly, two large families of applications based either on sonophysical $(20-100 \mathrm{kHz})$ or sonochemical (100-2000 kHz) effects provided by US can be distinguished, although sometimes both mechanisms are simultaneously involved to a different extent (for a detailed description of US effect depending on US parameters (power, frequency, etc.) and the mechanisms associated with each of them see Chapter 1). This general classification has been followed throughout this chapter to describe the most outstanding applications regarding US reactions and processes in which carbohydrates are involved. 


\subsection{Sonophysical Effects}

\subsubsection{Depolymerization}

It is known that polysaccharides constitute an important qualitative and quantitative source of valuable carbohydrates. However, their application for many chemical or biological uses requires a prior partial or total depolymerization, which is usually carried out by strong chemical or enzymatic hydrolysis following conventional methods. The possibility of applying emergent technologies such as US as an alternative or complement to these techniques for $M_{\mathrm{w}}$ reduction provides a powerful approach to increase depolymerization yield, decrease process time, and avoid undesired reactions.

Since the earliest works on the application of US for polymer degradation (Schmid and Rommel, 1939) a plethora of research has been focused on depolymerization of macromolecules, including polysaccharides. Although other mechanisms might be involved, macromolecule depolymerization can be explained as the result of different effects: (1) cavitation $(20-100 \mathrm{kHz})$, in which mechanical degradation takes place during the collapse of bubbles, which provokes an increase in temperature in the area of bubbles and pressure oscillations propagated through the material (Seshadri et al., 2003), and (2) chemical degradation due to the effect of hydroxyl radicals $(100-2000 \mathrm{kHz}$ ). The first of these effects is the most usual (Grönroos et al., 2004; Zhang et al., 2013a).

As a consequence of polysaccharide disruption, their physicochemical and functional properties can be modified in a different manner, depending on the processing conditions. In general, the type, $M_{\mathrm{w}}$, and concentration of polysaccharide, the US intensity and frequency, and the temperature and time of treatment are the most influential factors.

Whereas radical formation or thermal reactions by US can be more effective for compounds with low $M_{\mathrm{w}}$, the main effects for macromolecules are associated with mechanical sheared forces, which are more pronounced with the increase in the compound size. Thus, Portenlänger and Heusinger (1997) treated dextran at $35 \mathrm{kHz}$ to $1.6 \mathrm{MHz}$ for $150 \mathrm{~min}$ and found that the lowest frequency value was the most effective for degradation. Moreover, the mechanical forces were ineffective for dextran with $M_{\mathrm{w}}$ below 40,000. This could be due to the fact that the opportunities for interacting with the cavitation energy increase with $M_{\mathrm{w}}$ and small molecules have shorter relaxation times and can support the sonication stress more easily (Liu et al., 2006).

Chitosan, a polysaccharide prepared by $N$-deacetylation of chitin, is a biodegradable polysaccharide with excellent technological and functional properties. However, its limited solubility in neutral or alkaline media hampers its potential application, among others, in the food science and technology field. US can be used to decrease the $M_{\mathrm{w}}$ of chitosan and increase its solubility. Thus, the effect of US $\left(200 \mathrm{~W}, 80^{\circ} \mathrm{C}, 0-99 \mathrm{~h}\right)$ on chitosan of different $M_{\mathrm{w}}$ and deacetylation degree (DD) was investigated by Liu et al. (2006). The results showed that chitosan with higher $M_{\mathrm{w}}$ and DD was more easily degraded, and that the polydispersity ( $M_{\mathrm{w}}$ distribution) decreased with US treatment time, which was in linear correlation with the reduction in $M_{\mathrm{w}}$. However, Wu et al. (2008) did not find a clear relationship between the DD of chitosan and its depolymerization after sonication $\left(20 \mathrm{kHz}, 31-62 \mathrm{~W} \mathrm{~cm}^{-2}\right.$, 5-60 min). These discrepancies could be mainly due to the different conditions used in the studies. 
In another study on chitosan fragmentation, Kassai et al. (2008) found that the optimal conditions for preparation of smaller $M_{\mathrm{w}}$ fragments from larger macromolecules were low chitosan concentration $(0.2 \%)$ and an ultrasonic power of $90 \mathrm{~W}$. Although the effects of US generally increase with US intensity, this is only valid up to a certain value, since large amounts of cavitation bubbles could act as a barrier for energy transmission in the system. Zhang et al. (2013b) treated citrus pectin with US $\left(20 \mathrm{kHz}, 60-544 \mathrm{~W} \mathrm{~cm}^{-2}\right.$, pulsed $\left.2 \mathrm{~s} / 1 \mathrm{~s}, 0-40 \mathrm{~min}\right)$ and found an increase in galacturonic acid and rhamnose content with increasing US intensity, whereas mannose, galactose, and arabinose amount decreased. The atomic force microscopy analysis of the pectin thus treated revealed its degradation at the nano level.

In relation to temperature, and in order to get the maximum mechanical US effect, the assays should be carried out at the lowest temperatures possible (Mason and Lorimer, 2002). According to Hernoux-Villière et al. (2013), $60^{\circ} \mathrm{C}$ appeared to be the maximum temperature for cavitation bubbles to coalesce with vapor bubbles.

In general, degradation of polysaccharides increases with prolonged ultrasonication time. Liu et al. (2006) observed that polydispersity decreased with ultrasonic treatment time, which was in a linear relationship with the decrease in $M_{\mathrm{w}}$.

Whereas most studies on polysaccharide degradation are generally focused on evaluation of depolymerization extent and rate as a function of US conditions, current research is also addressing the evaluation of the effect of US in combination with free radicals generated by using different initiators $\left(\mathrm{H}_{2} \mathrm{O}_{2}\right.$, potassium persulfate (KPS), etc.). As an example, Prajapat and Gogate (2015) reported the combined use of ultrasonication $(20 \mathrm{kHz}, 100 \mathrm{~W}$, pulsed mode) and KPS as an initiator of the degradation of an aqueous solution of guar gum. Furthermore, the efficacy of combined schemes based on microwave and US on depolymerization of guar gum was also evaluated for the first time in this study. In general, the degradation rate increased with temperature and free radicals produced from dissociation of KPS due to US or microwave treatments. When considered individually, US provided a higher kinetic rate as compared to microwave irradiation. As for sequential approaches, microwave followed by US was the most effective. However, among all approaches considered, the use of US in combination with KPS at $50^{\circ} \mathrm{C}$ was the most effective for a reduction in the permanent viscosity of guar gum solutions (Table 17.1). Li and Feke (2015) also studied the influence of salt species $(\mathrm{NaCl}$ or $\mathrm{Na}_{2} \mathrm{SO}_{4}$ ) over degradation of xanthan, suggesting that different salt species and concentrations could increase or inhibit ultrasonic degradation by changing the molecular conformation of xanthan.

In a recent study by Čížová et al. (2015), degradation of mannan (up to $1 \mathrm{MDa}$ ) from Candida albicans was evaluated after ultrasonication $(20 \mathrm{kHz}, 60 \mathrm{~W}$, temperature below $50{ }^{\circ} \mathrm{C}$ ) and/or in situ generation of $\mathrm{OH} \cdot$ by the Fenton reaction. After 120 min of US treatment, low $M_{\mathrm{w}}$ mannan $(\sim 30 \mathrm{kDa})$ with narrow polydispersity index (1.8) was obtained, and the structure of the polysaccharide was widely preserved. Similar or even lower $M_{\mathrm{w}}$ (up to $16 \mathrm{kDa}$ ) mannan was obtained after freeradical degradation, but with an overall broadening of polydispersity index, which was more pronounced at higher concentrations of $\mathrm{Fe}^{2+}$. Noticeable changes in the structure of degraded mannan were also observed. 
Table 17.1 Comparison of sonication time required to reach final limiting viscosity $(\eta)$, percentage degradation, and first-order kinetic rate constant for treatment of guar gum solution using different approaches. Reprinted from Chemical Engineering and Processing 88, 1-9. Depolymerization of guar gum solution using different approaches based on ultrasound and microwave irradiations by Prajapat and Gogate (2015); with permission from Elsevier.

\begin{tabular}{|c|c|c|c|c|c|}
\hline Approach & $\begin{array}{l}\text { Sonication } \\
\text { time } \\
(\mathrm{min})\end{array}$ & {$[\eta]\left(\mathrm{mLg}^{-1}\right)$} & $\begin{array}{l}\text { Degradation } \\
(\%)\end{array}$ & $\begin{array}{l}\text { Kinetic rate } \\
\text { constant } \\
\left(\mathrm{min}^{-1}\right)\end{array}$ & $\mathbf{R}^{2}$ \\
\hline GG control & & 27.93 & & & \\
\hline US $\left(35^{\circ} \mathrm{C}\right)$ & 26 & 1.23 & 95.6 & 0.220 & 0.961 \\
\hline \multicolumn{6}{|l|}{ US+KPS (1 g) } \\
\hline $\mathrm{US}+\mathrm{KPS}\left(20^{\circ} \mathrm{C}\right)$ & 26 & 1.23 & 95.6 & 0.218 & 0.972 \\
\hline$U S+\operatorname{KPS}\left(25^{\circ} \mathrm{C}\right)$ & 26 & 1.23 & 95.6 & 0.218 & 0.967 \\
\hline US + KPS $\left(35^{\circ} \mathrm{C}\right)$ & 26 & 1.23 & 95.6 & 0.222 & 0.968 \\
\hline US + KPS $\left(42^{\circ} \mathrm{C}\right)$ & 20 & 1.06 & 96.2 & 0.310 & 0.976 \\
\hline \multicolumn{6}{|l|}{$\mathrm{US}+\mathrm{KPS}\left(50^{\circ} \mathrm{C}\right)$} \\
\hline US+KPS (0.1 g) & 30 & 1.23 & 95.6 & 0.194 & 0.969 \\
\hline US+KPS $(0.5 \mathrm{~g})$ & 12 & 0.67 & 97.6 & 0.414 & 0.980 \\
\hline US+KPS (1g) & 8 & 0.24 & 99.1 & 0.645 & 0.984 \\
\hline \multicolumn{6}{|l|}{$M W+K P S$} \\
\hline$M W+K P S(0.05 \mathrm{~g})$ & 32 & 1.4 & 94.99 & 0.142 & 0.978 \\
\hline$M W+K P S(0.1 \mathrm{~g})$ & 28 & 1.4 & 94.99 & 0.173 & 0.965 \\
\hline$M W+K P S(0.5 \mathrm{~g})$ & 14 & 0.67 & 97.6 & 0.412 & 0.980 \\
\hline MW + KPS (1 g) & 10 & 0.24 & 99.1 & 0.588 & 0.994 \\
\hline \multicolumn{6}{|l|}{$M W+U S+K P S$} \\
\hline$M W+U S+K P S+0.1 \mathrm{~g}$ & 26 & 1.06 & 96.2 & 0.171 & 0.964 \\
\hline $\mathrm{MW}+\mathrm{US}+\mathrm{KPS}+0.5 \mathrm{~g}$ & 22 & 0.24 & 99.1 & 0.249 & 0.968 \\
\hline$M W+U S+K P S+1 g$ & 14 & 0.24 & 99.1 & 0.356 & 0.986 \\
\hline \multicolumn{6}{|l|}{$U S+M W+K P S$} \\
\hline$U S+M W+K P S+0.1 \mathrm{~g}$ & 32 & 1.06 & 96.2 & 0.149 & 0.956 \\
\hline$U S+M W+K P S+0.5 g$ & 24 & 0.24 & 99.1 & 0.222 & 0.978 \\
\hline$U S+M W+K P S+1 g$ & 16 & 0.24 & 99.1 & 0.305 & 0.988 \\
\hline
\end{tabular}

GG control, guar gum untreated; US, ultrasound; MW, microwave; MW+US+KPS, sequential effect of microwave followed by ultrasound in presence of KPS; US + MW + KPS, sequential effect of ultrasound followed by microwave in presence of KPS.

\subsubsection{Effects of US on Functional Properties of Carbohydrates}

17.2.2.1 Technological Properties The modifications in the technological properties of polysaccharides after sonication have been extensively studied and mainly correlated with a reduction in their average $M_{\mathrm{w}}$. Panchev et al. (1994) intensified the process of pectin deesterification by combining acid maceration with US $(22 \mathrm{kHz}$, $1-1.2 \mathrm{~W} \mathrm{~cm}^{-2}, 24-30 \mathrm{~min}$ ) and found that a more prolonged US treatment resulted in pectin with lower gel strength. 
Bhaskaracharya et al. (2009) revised the positive influence of US on physical properties (turbidity, gelation, pasting properties, viscosity, flow behavior, swelling, solubility) of pectin, corn starch, and exopolysaccharides from Alteromonas macleodii, among others. Hydroxypropylmethylcellulose (HPMC) is another biopolymer whose functional properties have been US-modified. Camino et al. (2009) degraded HPMC of different $M_{\mathrm{w}}$ by US $\left(20 \mathrm{kHz}, 750 \mathrm{~W}\right.$, amplitude $\left.20 \%, 25^{\circ} \mathrm{C}\right)$ and found that high $M_{\mathrm{w}}$ HPMC presented structural modifications and changes in the viscosity and water mobility that were not apparent in the case of low $M_{\mathrm{w}}$ HPMC. Karaman et al. (2012) also observed a decreased in viscosity and other rheological parameters during the processing of glucomannan by US $(24 \mathrm{kHz}, 40-100 \%$ amplitude level, $\left.40-60^{\circ} \mathrm{C}, 3-11 \mathrm{~min}\right)$. Zhang et al. (2013a) studied the effect of US $(20 \mathrm{kHz}, 121-$ $362 \mathrm{~W} \mathrm{~cm}^{-2}$, pulsed $2 \mathrm{~s}$ on $/ 2 \mathrm{~s}$ off, $0-60 \mathrm{~min}$ ) in the treatment of apple pectin and observed a decrease in $M_{\mathrm{w}}$, probably attributable to the breakdown of the larger complexes and the decrease of neutral sugar side chains. This, together with a reduction in the esterification degree, gave rise to a marked diminution of viscosity. High intensity US $\left(24 \mathrm{kHz}, 200 \mathrm{~W}, 50-100 \%\right.$ amplitude, $\left.25-75^{\circ} \mathrm{C}, 10-30 \mathrm{~min}\right)$ was also shown to effectively decrease the intrinsic viscosity of an alginate solution; time and amplitude had a direct effect on the viscosity depression and temperature an inverse effect. Moreover, sonication decreased the subsequent interaction strength between this polysaccharide and $\beta$-lactoglobulin (Hosseini et al., 2013).

In the study by Venegas-Sánchez et al. (2013), US (23, 45 and $83 \mathrm{kHz}, 50 \mathrm{~W}, 5 \mathrm{~min})$ served as a stimulus to modify shear viscosity of carrageenan and agar; 23 and $83 \mathrm{kHz}$ presented the lowest effect. The influence of US on viscosity reduction depended on the polymer coil conformation, and the presence of $\mathrm{SO}_{3}^{-}$groups in the polysaccharides was shown to suppress the US effect. Fourier transform infrared (FT-IR) spectroscopy analyses revealed that US broke the hydrogen-bonded networks of the polysaccharides and water molecules could then be re-distributed into the $\mathrm{OH}$ groups of carrageenan.

The effect of polysaccharide structure on the changes in their rheological properties produced by US treatment $\left(20 \mathrm{kHz}\right.$, pulsed $5 \mathrm{~s}$ on $/ 5 \mathrm{~s}$ off, $\left.3.7-10.1 \mathrm{~W} \mathrm{~cm}^{-2}, 25^{\circ} \mathrm{C}\right)$ was also recently evaluated on guar, xanthan, and pectin dispersions by Tiwari et al. (2014). A significant reduction in apparent viscosity and a trend towards Newtonian flow behavior were observed. Changes in the rheological properties of pectin and guar were higher as compared to those of xanthan dispersions. The branching structure of this last polysaccharide could probably confer higher stability to it.

Chen et al. (2014) degraded an exopolysaccharide isolated from Cordyceps sinensis by US ( $20 \mathrm{kHz}, 750 \mathrm{~W}, 70 \%$ amplitude, $5-60 \mathrm{~min})$, and the fraction obtained exhibited an average $M_{\mathrm{w}}$ of $730 \mathrm{kDa}$ with much lower intrinsic viscosity and noticeably higher solubility in water than the original polysaccharide.

The physicochemical properties of corn starches with different amylose content after US treatment $\left(100 \mathrm{~W}, 30 \mathrm{~min}, 30^{\circ} \mathrm{C}\right)$ were studied by Luo et al. (2008). US caused alterations in granular structure, swelling power and solubility, gelatinization transition temperature, syneresis, and pasting properties. The results described in this paper revealed that US particularly degraded the amorphous areas and attacked linear amylose more easily than highly branched amylopectin molecules. Furthermore, in a study on the characterization of starch nanoparticles of Araucaria angustifolia seeds subjected to acid hydrolysis or US treatment $(100 \mathrm{~W}, 30$ cycles of sonication $1 \mathrm{~min}$ on/1 min off), Gonçalves et al. (2014) reported that the US-processed starch was the most similar to native starch, and only exhibited differences in regard to syneresis. 
17.2.2.2 Bioactive Properties As previously mentioned, the decrease in $M_{\mathrm{w}}$ caused by US can be accompanied by modifications in the bioactivity of polysaccharides. Despite the interest in increasing the knowledge and in the exploitation of bioactive carbohydrates, the number of studies addressing this issue is, to date, very limited. Liu et al. (2006) described an enhancement in the antimicrobial activity of chitosan after US treatment $\left(200 \mathrm{~W}, 80^{\circ} \mathrm{C}, 0-99 \mathrm{~h}\right)$ and indicated that $M_{\mathrm{w}}$ was a more important factor than DD on chitosan bioactivity. However, in previous papers (Rhoades and Roller, 2000; Jeon et al., 2001; No et al., 2002), an opposite effect was observed for chitosan samples obtained by enzymatic and oxidative-reductive degradation. These dissimilar results could be explained by the different degradation method employed which could modify, in a different manner, the chemical structure and chain conformation of chitosan. Recently, Guo et al. (2014) studied the effect of the duration (0-220 min), temperature $\left(5-45^{\circ} \mathrm{C}\right)$, sample concentration $\left(0.1-10 \mathrm{mg} \mathrm{mL}^{-1}\right)$, and input power level (5-45\%) on sea cucumber fucoidan degradation and its antioxidant activity. This bioactive property increased very rapidly during the first period of ultrasonication and then displayed a decrease as the treatment persisted. During the initial period of the process, the $M_{\mathrm{w}}$ of the fucoidan diminished promptly, leading to an increase in free hydroxyl groups and higher content of reducing sugars. At that point, the fragmentation of hydrogen bonds among the fucoidan molecules was the main cause affecting the decline of $M_{\mathrm{w}}$ and therefore their bioactivity. However, as the sonication continued, the polysaccharide chains were transformed into single chains and it was more difficult to fragment the molecules, thus lower mechanical effect could be involved, radical formation being, in this case, the predominant effect.

\subsubsection{Use of Ultrasound in Carbohydrate Chemistry}

As is known, US is an environmentally green technology with many applications in carbohydrate chemistry. The chemical and physical effects of US can improve the synthesis of carbohydrate derivatives by (1) acceleration of reaction and (2) using gentler physical conditions, thus US-treated carbohydrates have shown improved properties and functionality over non-US treated samples.

17.2.3.1 Acylation The role of US as a synthesis method has been evaluated as a way to improve the solubility in water of several carbohydrates (Brochette-Lemoine et al., 2000; Wang et al., 2009; Lu et al., 2013). To increase chitosan solubility, a novel chitosan derivative was synthesized by the acylation reaction of this polysaccharide with $p$-acetamidobenzoylate chloride in acetic acid medium under high-intensity US irradiation $\left(18 \mathrm{kHz}, 200 \mathrm{~W}, 1.5 \mathrm{~h}, 25^{\circ} \mathrm{C}\right.$, chitosan $/ p$-acetamidobenzoic acid ratio $\left.1: 2\right)$ (Wang et al., 2009). The derivative obtained under these conditions showed a maximum degree of substitution (DS) of 0.42 , as assessed by FT-IR spectroscopy and ultraviolet (UV) spectrophotometry, together with improved solubility and good UV absorption.

17.2.3.2 Esterification Sugar esters show a wide potential of application in the food field (e.g., as food emulsifiers), as well as in the cosmetic and pharmaceutical industries. Six novel raffinose long-chain fatty acid monoesters obtained from three different acyl donors (methyl caprylate, methyl laurate, and methyl stearate) and acylated at different positions (1- $O$-monoester or 6-O-monoester) were synthesized 
under reduced pressure and US irradiation by Lu et al. (2013). Optimal conditions for acylation were molar ratio of raffinose to fatty acid methyl ester of 2:1, anhydrous $\mathrm{K}_{2} \mathrm{CO}_{3}$ mol percentage with respect to raffinose of $12 \%, 40 \mathrm{kHz}, 2 \mathrm{~h}, 65^{\circ} \mathrm{C}$, and $10 \mathrm{kPa}$ ). Among the six novel sugar esters, 6 - $O$-octanoylraffinose and 1-O-octanoylraffinose showed the highest hydrophile-lipophile balance value (up to 15.1). All six monoesters showed similar melting points $\left(190-194^{\circ} \mathrm{C}\right)$.

17.2.3.3 Oligomerization US has also been described as promoting the catalysis of the Fischer glycosylation reactions of alcohols by acidic clays (e.g., montmorillonite $\mathrm{KSF} / \mathrm{O}$ ), giving rise to an increase in the conversion rate of carbohydrates and to improved yields of oligomeric species (Brochette et al., 1997; Brochette-Lemoine et al., 2000).

17.2.3.4 0xidation The salt complexation properties of oxidized carbohydrates are mainly due to carboxylic acid functions. Uronic acids can be obtained by the TEMPO ((2,2,6,6-tetramethylpiperidin-1-yl)oxyl) mediated oxidation of the primary alcohols of carbohydrates by using $\mathrm{NaOCl}$. Brochette-Lemoine et al. (2000) studied the effect of US irradiation on this oxidation when applied to methyl $\alpha$ - $D$-glucoside and sucrose. For both substrates, a rate enhancement was observed for this experiment as compared to the classical one. Changes in US characteristics (acoustic power, probe diameter, and frequency) also showed an effect on production of radicals and on the rate of oxidation. In general, application of a higher frequency increased the oxidation rate, albeit to the detriment of yield.

17.2.3.5 Isomerization Isomerization of carbohydrates is another chemical reaction of importance in processed foods than can take place under ultrasonic conditions. As an example, Corzo-Martínez et al. (2014) reported for the first time the use of high-intensity US $(20 \mathrm{kHz}, 400 \mathrm{~W}, 70 \%$ amplitude, $13 \mathrm{~mm}$ tip, $120 \mu \mathrm{m})$ for isomerization of lactose in basic media as an approach to speed up the synthesis of lactulose. In general, in a buffered system ( $\mathrm{pH} 10)$, US at $70 \%$ amplitude and $60^{\circ} \mathrm{C}$ increased the rate of lactose isomerization. Under these conditions, higher values of lactulose, epilactose, and galactose were obtained in comparison to conventional heating.

\subsubsection{Crystallization}

The quality of foods is influenced by the size of undissolved sugar crystals disseminated in the matrix, and sugar size also affects the rate of dissolution of sugar crystals in food preparations. Control of crystal size distribution is therefore critical, and in some cases it is difficult to obtain products with the highest quality and with an extended shelf-life. In general, solvent evaporation and temperature change tactics are usual and two different stages, nucleation and crystal growth, can be distinguished. The use of US during crystallization is referred to as sonocrystallization, which offers potential advantages to diminish variability under these situations. Sonication improves both the nucleation and crystal growth rates in a saturated or supercooled medium due to cavitation bubbles acting as nuclei for crystal growth and/or disruption of crystals previously present within the system and, therefore, increasing the number of nucleation sites (Chemat et al., 2011; Hartel, 2013). Chow et al. (2005) showed through direct imaging of a sucrose solution (15\%) that cavitational 
(a)

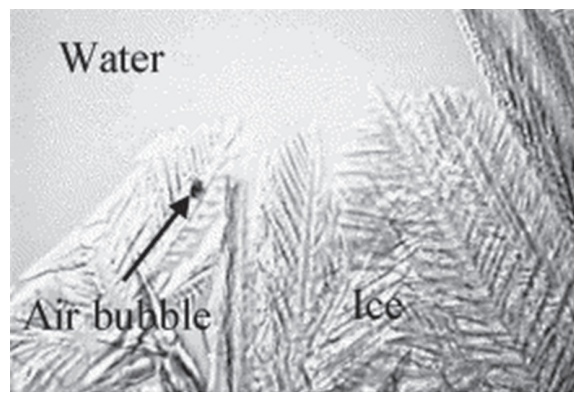

(c)

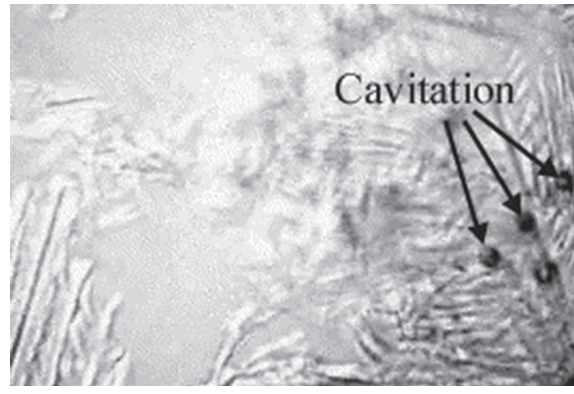

(b)

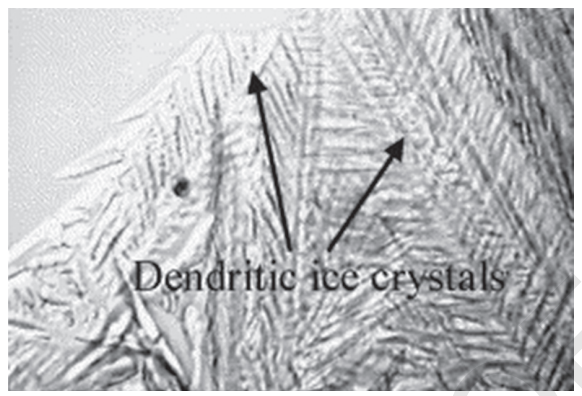

(d)

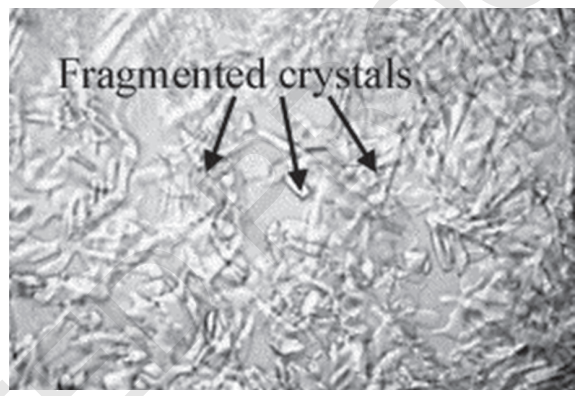

Figure 17.1 (a) Secondary nucleation of ice in $15 \%(w / w)$ sucrose solution-ice dendrite formed due to freezing without ultrasound. (b) Ice dendrite growth with freezing no ultrasound. (c) Fragmentation of ice dendrites after $2 \mathrm{~s}$ of ultrasound application. (d) Fragments of crystals remaining after $4 \mathrm{~s}$ of ultrasonic treatment. Reprinted from Ultrasonics Sonochemistry 11, 245250. The microscopic visualization of the sonocrystallisation of ice using a novel ultrasonic cold stage by Chow et al. (2004); with permission from Elsevier.

micro-bubbles can certainly act as nucleation sites (Figure 17.1). According to Deora et al. (2013), sonocrystallization has several benefits, such as better product and process consistency, improved crystal purity and secondary physical characteristics of the material, smaller crystallization phase times, and less frequent rework. In spite of these advantages, its application on an industrial scale in the food field is still underdeveloped, mainly due to the lack of appropriate sonoreactors, and most studies to date are laboratory-scale approaches.

Ruecroft et al. (2005) observed a significant reduction in temperature below the solid starts to separate spontaneously for a given supersaturation level for supersaturated sugar solutions (mono and disaccharides) under the following US conditions: $20 \mathrm{kHz}, 30 \mathrm{~s}, 35 \mathrm{~W} \mathrm{~L}^{-1}$. Bund and Pandit (2007) reported a 92\% crystallization recovery (as compared to $15 \%$ for mechanically stirred samples) for lactose solutions treated in an ultrasonic bath $(22 \mathrm{kHz})$ with $85 \%$ ethanol as anti-solvent. However, Hu et al. (2006) did not observe any positive effect of US treatment $(20 \mathrm{kHz}, 2000 \mathrm{~W})$ on the sugar quality of evaporative systems. The sonocrystallization of foods was also found to promote sucrose refining, as indicated by Stasiak and Dolatowski (2008).

Honey is considered to be a supersaturated solution of glucose with a high tendency to spontaneously crystallize at ambient temperature as glucose monohydrate. 
To avoid this, heat treatment is traditionally used, with consequent modifications in honey quality. Thus, during the last few years the search for alternative treatments, such as those based on power US, has attracted wide interest. As recently reviewed by Deora et al. (2013), the advantages of this technique for honey processing include the elimination of existing crystals and the delay of crystallization, under low temperature conditions, and with no significant effects on honey quality parameters.

\subsection{Sonochemical Effects on Carbohydrate Depolymerization}

As has been indicated above, ultrasonic irradiation, under either low or high energy conditions, has proved to be a suitable method to carry out the depolymerization of high $M_{\mathrm{w}}$ carbohydrates. A number of mechanisms, namely mechanochemistry, solvent radical-induced reactions, and pyrolysis, have been described as being involved in US degradation of polysaccharides. However, it is generally accepted that at a low frequency $(20 \mathrm{kHz})$, degradation is mainly caused by the mechanical effect of cavitation rather than by radical formation. On the contrary, in high-frequency US $(>100 \mathrm{kHz})$ treatments, radical formation is expected to be important. It is also worth noting that pyrolysis, as a local phenomenon limited to the surface of the cavitation bubbles, is only expected to exert an effect in the case of hydrophobic samples (Kardos et al., 2001).

Whereas the effect of low frequency US on degradation of different polysaccharides has been widely evidenced (see section 17.2.1), mechanistic considerations have not been generally addressed, particularly for those studies involving the use of low-intensity US. Portenlänger and Heusinger (1997) investigated the ratio of mechanical and radical effects for the ultrasonic degradation of aqueous solutions of dextran as a function of US frequency $(35,500,800 \mathrm{kHz}$, and $1.6 \mathrm{MHz})$ and $M_{\mathrm{w}}$ $(500,200,110$, and $40 \mathrm{kDa})$. As compared to other US frequencies, treatments at $35 \mathrm{kHz}$ provided the most effective degradation together with the narrowest $M_{\mathrm{w}}$ distribution. Under these conditions, scission of the polymer chain strongly increased with $M_{\mathrm{w}}$ as a result of the predominant mechanical effects of US. For other frequencies, no dependence between the effectiveness of bond break and $M_{\mathrm{w}}$ was found. At higher frequencies $(>500 \mathrm{kHz})$, only radical reactions were responsible for the degradation.

Czechowska-Biskup et al. (2005a) reported US treatment at $360 \mathrm{kHz}$ as an efficient procedure for reducing the $M_{\mathrm{w}}$ of chitosan and starch in aqueous solutions. Under these frequency conditions, degradation was caused by both $\mathrm{OH}$ radicals and mechanochemical effects. Sonochemical yield was also shown to be dependent on polymer concentration (Figure 17.2), US power, and gas used to saturate the solution. Thus, in air-saturated chitosan solutions at $\mathrm{pH} 3$, and using an US power of $100 \mathrm{~W}$, the average chain scission yield in the range $0-90$ min was calculated as approximately $8 \times 10^{-11}$ mol $\mathrm{J}^{-1}$. US degradation of starch showed a lower yield, probably due to the different chain conformation of starch macromolecules.

In another paper by the same authors (Czechowska-Biskup et al., 2005b), degradation of chitosan by using three physical methods (irradiation in dry state, irradiation in aqueous solution, and sonication in aqueous solution) were compared in terms of yields and side effects. Although all techniques were efficient for controlled reduction of the average $M_{\mathrm{w}}$ of chitosan, yields and extent of formation of carbonyl groups 


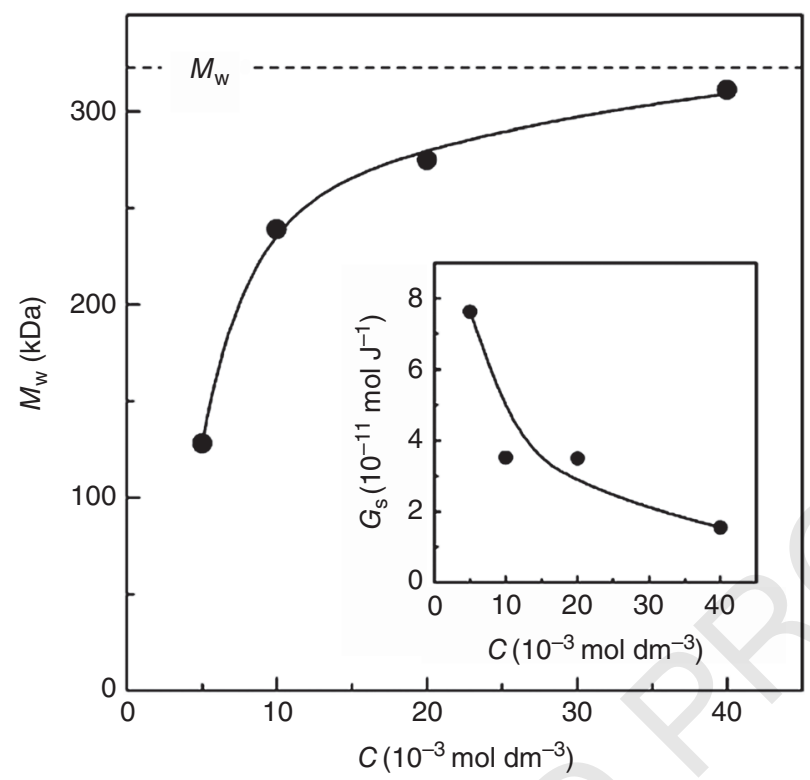

Figure 17.2 Sonolysis of chitosan $\left(10 \mathrm{~min}, 360 \mathrm{kHz}\right.$, nominal power $100 \mathrm{~W}$, dose rate $170 \mathrm{~W} \mathrm{~kg}^{-1}$, $\left.22^{\circ} \mathrm{C}\right)$ in air-saturated aqueous solution at pH $3.0\left(\mathrm{HClO}_{4}\right)$. Average molecular weight $\left(\mathrm{M}_{\mathrm{w}}\right)$ after sonication as a function of chitosan concentration. Broken line denotes the starting molecular weight. Inset: Yield of chain scission as a function of chitosan concentration. Reprinted from Carbohydrate Polymers 60,175-184. Degradation of chitosan and starch by 360-kHz ultrasound by Czechowska-Biskup et al. (2005a); with permission from Elsevier.

under radiation (both in the solid state or in $\mathrm{N}_{2} \mathrm{O}$-saturated aqueous solutions) were similar. In regard to degradation yield, sonication was shown to be less efficient, but the availability of equipment providing high dose rates also makes this technique attractive. Reduction in $M_{\mathrm{w}}$ of chitosan also led to a significant increase in its fatbinding capacity, making this degraded polysaccharide of interest as an active food additive.

In a study by Hernoux et al. (2013), depolymerization of potato starch under single low ( $24 \mathrm{kHz}$ US bath) and high (piezoceramic $500 \mathrm{kHz}$ reactor) frequency US irradiation showed higher yields of reducing sugars, as compared to conventional heating. Based on these results, in a further study by the same authors, a novel US reactor with dual coaxial frequencies was developed to focus both mechanical and chemical US effects on a concentrated area for greater efficiency. This prototype was successfully employed to depolymerize a potato starch-based industrial waste (potato peels). A liberation of reducing sugars up to $48 \%$ within $2 \mathrm{~h}$ under acidic conditions was observed. This reactor, which combines efficient stirring provided by low frequency and chemical radicals produced at higher frequency, may allow an eventual scale-up and a continuous flow could be considered (Hernoux-Villière et al., 2013). Similarly, ultrasonication with dual-frequency $(25 \mathrm{kHz}$ and $80 \mathrm{kHz})$ has also been reported to provide a higher degradation of starch chains, as compared to single-frequency treatments (25 kHz vs. $80 \mathrm{kHz})$ (Zheng et al., 2013). 


\subsection{Effects of Ultrasound on Biotechnological Processes}

US has become a widely accepted technique in a large variety of biotechnological applications, such as those aimed at improving the productivity of biological processes with carbohydrates as their substrate. The generation of cavitation bubbles causes damage to biological molecules, but recent studies have described the use of sub-lethal doses of US irradiation leading to beneficial effects in many bioprocesses (Yeo and Liong, 2013; Chatel et al., 2014). In these procedures, US irradiation can be applied over different enzymatic systems (hydrolysis of biopolymers, synthesis of compounds) or live biological systems (cell cultures, microbial fermentations), and the systems can be homogeneous or quasi-homogeneous, heterogeneous or biphasic.

The US/enzyme or living cell combination generally improves the chemical production or reduces the reaction time of bioprocesses involving carbohydrates. Four types of factors should be taken into account to enhance the performance of these processes: (1) US parameters (frequency, intensity, power, amplitude, hydrostatic pressure, mode (continuous or discontinuous), geometry of the reactor, US density, sonication time), (2) solution properties (solvent, temperature, $\mathrm{pH}$, nature of dissolved gas), (3) subtract characteristics (particle size, type of carbohydrate, $M_{\mathrm{w}}$, solubility, concentration), and (4) specific enzyme or live biological systems.

Regarding live biological systems, one of the original uses of power US in biochemistry was to break down biological cell walls, thereby increasing membrane permeability to liberate the content (Mason et al., 1996; Rokhina et al., 2009) (Figure 17.3). It is noteworthy that extensive membrane permeabilization by these physical treatments could be detrimental to cell viability and lead to lower yield (Yeo and Liong, 2013). The alteration induced by US leads to the rupture and pore formation on the membrane lipid bilayers, allowing transport of macromolecules (enzymes) across the semipermeable membrane. Moreover, the application of low-power US can also increase growth in microbial cell cultures, but high power causes cell disruption and hence it can be considered as a microbicide treatment (Kwiatkowska et al., 2011).

There are numerous studies on US effect over discrete enzyme systems for production of important compounds for the food industry. US has the potential to greatly influence the activity of enzymatic processes, and a dependence on the enzymatic activity with the intensity of sonication rather than with frequency of sonication has been found (Bashari et al., 2013). In general, the conditions most frequently used to enhance the physical effects on enzyme activation and reaction medium are lowfrequency US $(<50 \mathrm{kHz})$ and low-intensity US. Gogate and Kabadi (2009) suggested that sonochemistry and cavitation effects on enzymatic processes enhance enzyme diffusion, decrease transportation barriers, stabilize enzymes in solution, show influence on enzymatic reactivity, and improve mixing and mass transfer.

The following can be distinguished with respect to the type of system in which US is applied:

- Homogeneous or quasi-homogeneous systems in which enzymes or cells are dissolved or suspended. Examples of this type based on harvesting of intracellular substances without killing or disrupting cells are used for production of lactosehydrolyzed fermented milk, among other applications (Chemat et al., 2011). 


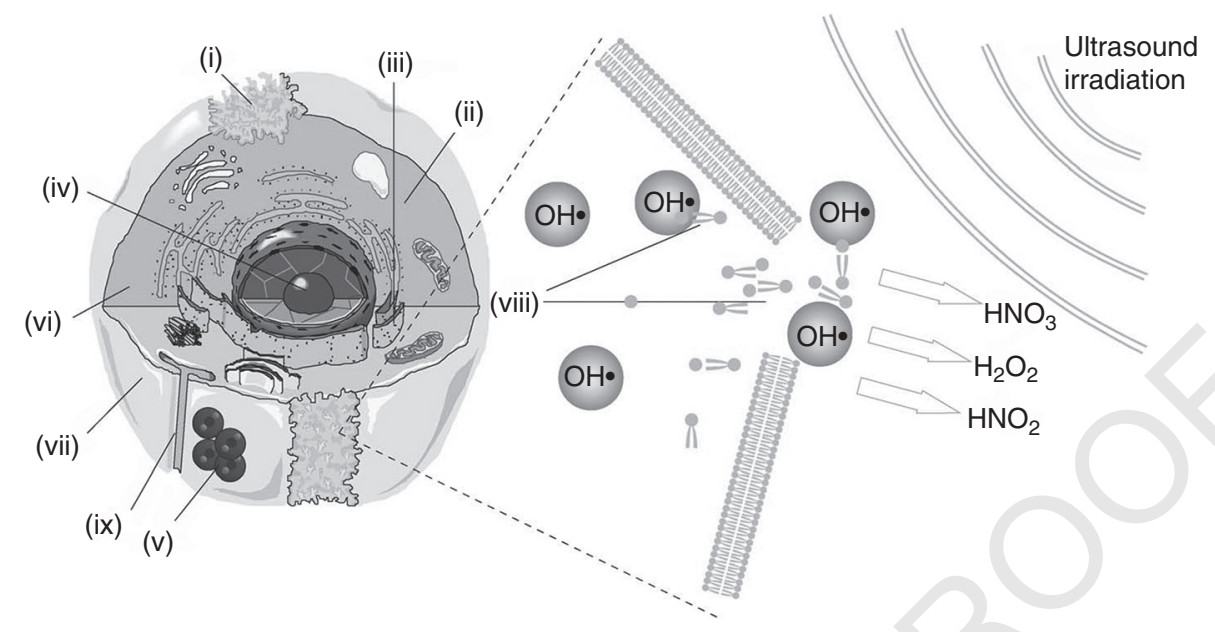

Figure 17.3 Molecular effects of ultrasound. Reprinted from Trends in Biotechnology 27 (5), 298-306. Low-frequency ultrasound in biotechnology: state of the art by Rokhina et al. (2009), with permission from Elsevier. Physical changes: (a) Thermal effects: (i) cell damage partial and full lysis; (b) non-thermal (cavitation and shearing) effects: (ii) changes to ultra-structures within cells; (iii) modified enzyme stability; (iv) nucleus rupture and release of DNA; (v) breakage of extracellular polymer substances; (vi) altered membrane permeability (enhanced mass transport inside and outside the cell); (vii) alteration of cell surface charge. Chemical changes (cavitation-induced generation of radicals): (viii) release of compounds (nitric acid, nitrous acid and hydrogen peroxide); (ix) decreased cellular stability.

- Heterogeneous bioreaction systems with insoluble substrate or using immobilized enzymes or cells (e.g., hydrolysis of starch or maltose with an immobilized glucoamylase). The reaction rate enhancement is attributed to the increase in the mass transfer, especially within the unstirred diffusion layer around the particles (Wang et al., 1996). The general stages of an enzymatic reaction on a solid substrate are shown in Figure 17.4.

- In biphasic system reactions, the reaction rate enhancement is due to the increase in the mass transfer through the boundary layers between the two phases (Chatel et al., 2014).

The following sections include a description of different studies in which US can be used as a way to intensify the processes in which enzymes are involved in carbohydrate reactions.

\subsubsection{Depolymerization}

Degradation of polysaccharides is one of the oldest applications of US in the biotechnology field (Chemat et al., 2011). In these processes, an enzyme or cell/US combination can be an efficient tool for biomass treatment (pretreatment, hydrolysis, and/or fermentation). The studies available in the literature regarding the use of US on bioprocesses are generally categorized into two main groups: simultaneous and sequential approaches. 


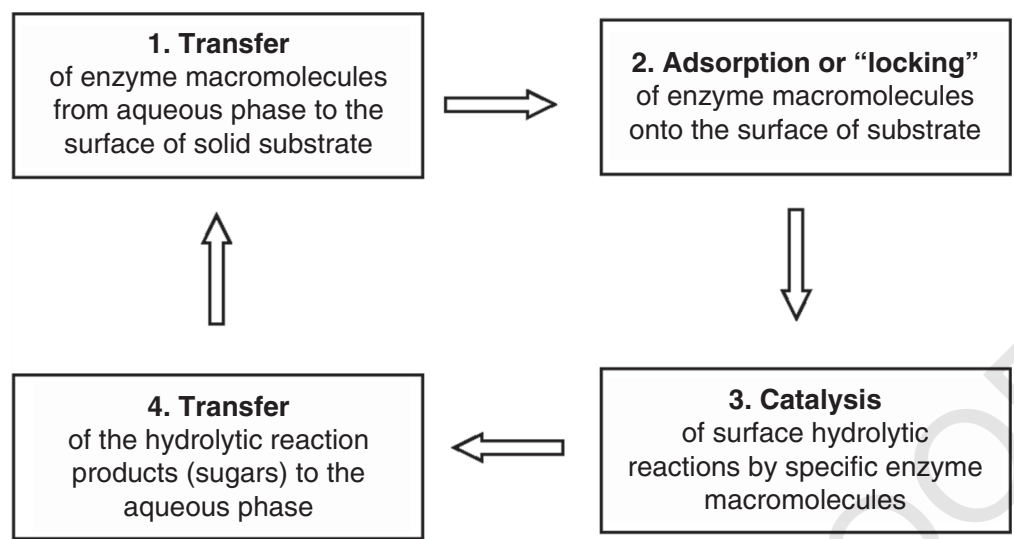

Figure 17.4 The general stages of an enzymatic reaction on a solid substrate. Reprinted from Biotechnology Advances 29, 768-780. Stimulation of bioprocesses by ultrasound by Kwiatkowska et al. (2011); with permission from Elsevier.

\subsubsection{Simultaneous Application}

When US is used in simultaneous approaches, the mechanism of action is unclear, but Yachmenev et al. (2009) suggest that (1) cavitation effects enhance the transport of enzyme macromolecules to the surface of the substrate (this effect is especially important in immobilized systems), (2) opening up the surface of solid substrate to the action of enzymes as a result of mechanical impact of cavitation is achieved, and (3) optimum enzyme temperature coincides with maximum cavitation.

The influence of US waves on the activity and stability of enzymes has been shown to be specific for each enzyme and dependent on sonication parameters (Barton et al.,1996; Özbek and Ülgen, 2000). Among others, the level of US intensity has been described as playing an important role in the activity or inactivity of many enzymes (Demirhan and Özbek, 2009). Thus, some researchers reported that the activity of free enzymes increased under mild US irradiation (Sakakibara et al.,1996; Özbek and Ülgen, 2000), whereas high-intensity US can cause denaturation.

Considerable effort has recently been devoted to extending the combined use of US and enzymes to enhance the depolymerization of numerous substrates. Regarding starch, the main polysaccharide in food industry, the application of US has been shown to significantly increase its conversion into glucose (Barton et al., 1996). Thus, at low starch concentrations $\left(8 \mathrm{~g} \mathrm{~L}^{-1}\right)$ and using $\alpha$-amylase (EC 3.2.1.1), an increase $(50 \%)$ in hydrolysis rate was observed with sonication $\left(60 \mathrm{~W}, 0.35 \mathrm{~W} \mathrm{~mL}^{-1}, 40^{\circ} \mathrm{C}\right.$, $10 \mathrm{~min})$. At higher starch concentrations $\left(15-50 \mathrm{~g} \mathrm{~L}^{-1}\right)$, both sonicated and unsonicated samples showed similar rates. On the other hand, no significant differences were observed in the rate of reaction for sonicated and unsonicated samples of soluble glycogen (Barton et al., 1996). In another study for the preparation of microporous starch with glucoamylases, ultrasonication was included before $(40 \mathrm{kHz}$, 100-300 W, 10-50 min), during (1,3, and 5 min every half an hour), and after enzyme incubation (time 5h) (Wu et al., 2011). The best degree of hydrolysis and oil absorption was obtained at $200 \mathrm{~W}$, for $50 \mathrm{~min}$ during glucoamylase digestion. Recently, Leaes et al. (2013) evaluated the influence of other factors such as solid-to-liquid ratio and concentrations of $\alpha$-amylase and amyloglucosidase on the amount of fermentable 
sugars released from cassava (Manihot esculenta) waste, in the presence or absence of US irradiation $\left(40 \mathrm{kHz}, 132 \mathrm{~W}, 55^{\circ} \mathrm{C}, 8 \mathrm{~h}\right)$. For a solid-to-liquid ratio of $0.4 \% \mathrm{w} / \mathrm{w}$, $12.2 \%$ of amyloglucosidase, and $8.0 \%$ of $\alpha$-amylase, the yields of fermentable sugars released were 116.1 and $83.1 \mathrm{~g} \mathrm{~L}^{-1}$ for US-treated and non US-treated samples, respectively. Moreover, in another study by $\mathrm{Hu}$ et al. (2013), $\alpha$-amylase and dual-frequency US $\left(25 \mathrm{kHz}+40 \mathrm{kHz}, 1.7 \mathrm{~W} \mathrm{~cm}^{-2}, 90 \mathrm{~min}, 60^{\circ} \mathrm{C}\right)$ were shown to promote starch hydrolysis, decreasing its viscosity and granular size, and forming deeper holes, as compared to the $\alpha$-amylase treatment without US.

Cellulosic materials are other substrates for obtaining glucose. The simultaneous use of US and enzymes increases the amount of available biopolymer in some processes, whilst in others it enhances the release of glucose. A kinetic study of the enhancement of hydrolysis of cellulosic materials with continuous US irradiation $\left(20 \mathrm{kHz}, 15-60 \mathrm{~W}, 45^{\circ} \mathrm{C}\right)$ and cellulase from Trichoderma viride was described by $\mathrm{Li}$ et al. (2005). The saccharification rate was enhanced using an irradiation intensity of $30 \mathrm{~W}$. However, the efficacy was reduced as the reactor size becomes larger, probably due to a decrease in US intensity per reaction volume.

The utilization of low-energy US $\left(50 \mathrm{kHz}, 13 \mathrm{~A}, 50^{\circ} \mathrm{C}, 8 \mathrm{~h}\right)$ during the enzymatic hydrolysis of other by-products such as corn stover and sugar cane bagasse greatly improves enzyme efficiency (20-40\%) (Yachmenev et al., 2009). More recently, US treatment $\left(40 \mathrm{kHz}, 100 \mathrm{~W}, 13 \mathrm{~mm}\right.$ tip, $\left.33 \mathrm{~W} \mathrm{~cm}^{-2}, 50^{\circ} \mathrm{C}, 65 \mathrm{~min}\right)$ has been applied to hydrolyze cellulose (Szabo and Csiszar, 2013). During sugar production, the reduction of $M_{\mathrm{w}}$ of dextran is important to avoid difficulties in processing. Thus, dextran has been treated with dextranases (E.C. 3.2.1.11) and sonication with the aim of reducing the viscosity of juices and obtaining isomaltooligosaccharides with prebiotic properties. In a recent research work by Bashari et al. (2013), the effect of US in combination with enzymes for the hydrolysis of dextran, together with the kinetic parameters of this reaction, were investigated. The maximum activity of dextranase was observed when the sample was treated with US $\left(25 \mathrm{kHz}, 40 \mathrm{~W}, 50^{\circ} \mathrm{C}, 15 \mathrm{~min}\right)$. Under these conditions, the enzymatic activity increased by $13.4 \%$ as compared to incubation at $50^{\circ} \mathrm{C}$. The kinetics parameters, maximum rate of reaction $\left(V_{\max }\right)$ and the Michaelis constant $\left(K_{\mathrm{M}}\right)$, also increased with US treatment. This effect could be explained by the influence of US irradiation on the secondary structure of dextranase. US irradiation increased the number of tryptophans on the dextranase surface and increased $\alpha$-helix conformation by $15.7 \%$ and reduced random coil by $5.4 \%$. In a further work by the same authors (Bashari et al., 2014), the combined effect of US and high hydrostatic pressure (HHP) produced a synergistic effect on the degradation of dextran catalyzed by dextranase. The production of isomaltose under US $(25 \mathrm{kHz}, 40 \mathrm{~W}, 15 \mathrm{~min}$ ) in combination with HHP (400 MPa for $25 \mathrm{~min}$ ) was $45 \mathrm{mg} \mathrm{mL}^{-1}$, as compared with $20 \mathrm{mg} \mathrm{mL}^{-1}$ obtained by incubation at $50^{\circ} \mathrm{C}$. Again, the effect of these combined treatments on the secondary structure of dextranase could explain these results.

The combination of US and cellulase has also been applied to guava (Psidium guajava) juice processing to improve its quality. Whereas the levels of total sugars, phenols, and antioxidant activity increased, the ascorbic acid content of the resulting juice decreased (Nguyen et al., 2013).

17.4.1.2 Sequential Application The use of US as pre-treatment of a substrate is the most common sequential process in which US is involved. The main effect obtained is the reduction of the particle size and, consequently, the increase in the catalytic 
surface area, and the reduction of the mass transfer limitations. The cavitation generates powerful hydro-mechanical shear forces in the bulk liquid, which disintegrate nearby particles (Chatel et al., 2014). Subhedar and Gogate (2013) established that US-assisted pre-treatment was better in the hydrolysis process because of the reduction of the structural rigidity of polysaccharides and the elimination of masstransfer resistances. The major advantages of US pre-treatment were the reduction of processing time, the operation at lower temperatures and the need for lower amounts of reactants (e.g., enzymes).

In the starch industry, US could be used as a pre-treatment to enhance the production of glucose from different grains (Khanal et al., 2007; Shewale and Pandit, 2009). Khanal et al. (2007), using a bench-scale US unit for sample pre-treatment $(20 \mathrm{kHz}$, horn $13 \mathrm{~mm}, 274-475 \mathrm{~W}$, during 20 or $40 \mathrm{~s}$ ), reported the enhanced glucose release from corn exposed to $\alpha$-amylase and glucoamylase. US treatment decreased the corn particle size nearly 20 -fold and this reduction was directly related to the power level and the sonication time. It is interesting to note that in all experimental sets there were three inflection points at 50,120, and $800 \mathrm{~nm}$, corresponding to individual starch molecules, clusters, and original grain. In addition, the scanning electron microscopy (SEM) micrographs of sonicated samples showed micropores and disruption of cell walls in corn mash. In this assay, enzyme addition during sonication $(274 \mathrm{~W}, 40 \mathrm{~s})$ gave higher glucose yields (32\%) than enzyme addition after US treatment. Likewise, the average particle size of sorghum flour slurry $(30 \% \mathrm{w} / \mathrm{v}$ at $\mathrm{pH} 6)$ pre-treated with a US horn $(20 \mathrm{kHz}, 750 \mathrm{~W}$, probe $13 \mathrm{~mm}, 1 \mathrm{~min})$ decreased from 302 to $163 \mu \mathrm{m}$ at $40 \%$ amplitude and to $115 \mu \mathrm{m}$ at $100 \%$ amplitude, while the percentage of saccharification increased by about $8 \%$ (Shewale and Pandit, 2009). The cavitation phenomena may release starch granules by disrupting the protein matrix surrounding the starch granules and the amylose-lipid complex.

Another substrate, maize mash, was sonicated at $20 \mathrm{kHz}$ and $4.8-8.3 \mathrm{~W} \mathrm{~mL}^{-1}$ for $40 \mathrm{~s}$, and treated with $\alpha$-amylase and glucoamylase to hydrolyze the polysaccharide into fermentable sugars (Montalbo-Lomboy et al., 2010). An increase in starch conversion (from $11 \%$ for the control to about $67 \%$ for the sonicated samples) was observed. SEM pictures revealed that starch was partially gelatinized during sonication and that the swelling power increased. Nikolic et al. (2010) reported longer treatments $\left(5 \mathrm{~min}, 60^{\circ} \mathrm{C}\right)$ at a higher frequency $(40 \mathrm{kHz})$ for achieving an increase in glucose concentration of $6.8 \%$ over an untreated control sample. Recently, US pre-treatment has been described as improving sugar production from potato pulp hydrolyzed by cellulase, thereby extending the practical application of potato pulp in the food industry. Sonication at $20 \mathrm{kHz}, 200 \mathrm{~W}$ for $10 \mathrm{~min}$ provided glucose and reducing sugar contents of 404 and $242 \mathrm{mg} \mathrm{g}^{-1}$, respectively, as compared to 251 and $172 \mathrm{mg} \mathrm{g}^{-1}$ obtained for a control sample (Miao et al., 2014). In cellulosic material, higher enzymatic hydrolysis yields after US pre-treatment are explained since cavitation effects greatly enhance the transport of water toward the crystalline cellulose.

Pre-treatment with US has also been combined with supercritical carbon dioxide (SC- $\left.\mathrm{CO}_{2}\right)$ to improve enzymatic hydrolysis processes. Thus, sugarcane bagasse $(65 \%$ $\mathrm{w} / \mathrm{w})$ was first treated in a US bath $\left(40 \mathrm{kHz}, 154 \mathrm{~W}, 2 \mathrm{~h}\right.$ at $\left.30^{\circ} \mathrm{C}\right)$, and later with $\mathrm{SC}-\mathrm{CO}_{2}$, and the amount of fermentable sugar obtained by enzymatic hydrolysis increased about $16 \%$ in comparison with the treatment using only US (Benazzi et al., 2013). However, considering the complexity of SC- $\mathrm{CO}_{2}$ treatment, the advantages of using this sequential process should be counterbalanced. 
The sequential application of US and enzymes also allows bioactive compounds such as xylooligosaccharides (XOS) to be used as prebiotic ingredients (Yang et al., 2011). When lignocellulosic material was pre-treated by sonication $(200 \mathrm{~W}, 30 \mathrm{~min}$, $1 \% \mathrm{NaOH}$ solution) under the optimal enzymatic condition $\left(25 \mathrm{U} \mathrm{g}^{-1}\right.$ substrate, $\mathrm{pH} 5.4,50^{\circ} \mathrm{C}$ ), the conversion of XOS was increased from $36.8 \%$ to $43.8 \%$. The main hydrolysis products were xylobiose, xylotriose, and xylotetraose.

Very few studies have been published on enzymatic hydrolysis followed by sonication. Kim et al. (2008) reported that it is possible to modify enzymatically hydrolyzed starch by applying US. Thus, the US treatment $\left(20 \mathrm{kHz}, 300 \mathrm{~W}, 4^{\circ} \mathrm{C}, 7 \mathrm{~min}\right)$, in ethanol, of a $2 \%(\mathrm{w} / \mathrm{v})$ hydrolyzed starch solution increased the starch particle diameter, indicating that it might be swollen or aggregated into clusters. Sonication has also been used after enzymatic hydrolysis to obtain nanofibers of sugarcane bagasse and curauá (de Campos et al., 2013). As the enzymatic treatment gave heterogeneous cellulose macrofibers, subsequent sonication was necessary for increasing the homogeneity. Thus, the freeze-dried enzyme-treated samples were dispersed in water $(1 \%, \mathrm{w} / \mathrm{v})$ using a US probe ( $13 \mathrm{~mm}$ horn, $3 \mathrm{~mm}$ microtip, $40 \mathrm{kHz}, 450 \mathrm{~W}, 50 \%$ amplitude, $20 \mathrm{~min}$ ), and long and entangled nanofibers were released.

\subsubsection{Other Bioprocesses}

In addition to the large body of research addressing the enzymatic depolymerization of polysaccharides affected by US, considerable research effort has also been invested in the evaluation of the potential of US in different bioprocesses involving enzymes, such as fermentation or production of biomass or specific metabolites. However, the number of papers devoted to the enzymatic modification of carbohydrates is still scarce.

17.4.2.1 Hydrolysis Some glycosidases of paramount industrial importance, such as invertase (EC 3.2.1.26), an enzyme which hydrolyzes sucrose, are affected by US and therefore have been extensively studied. Barton et al. (1996) observed a marked increase in invertase activity towards sucrose over a wide range of substrate concentrations $(0.1-2 \mathrm{M})$ using a US bath $\left(60 \mathrm{~W}, 0.35 \mathrm{~W} \mathrm{~mL}^{-1}, 40^{\circ} \mathrm{C}\right)$; an increase of $37 \%$ was found under optimal conditions $(0.9 \mathrm{M})$. The most likely factors explaining these results were the improved efficiency of mixing and the disruption of intraand intermolecular interactions at high substrate concentrations provided by US. Furthermore, the activity of the invertase increased by around $30 \%$ using an US generator $(815 \mathrm{kHz})$, operating at $\mathrm{pH} 4$ and $25^{\circ} \mathrm{C}$ during $4 \mathrm{~h}$, and with a low sucrose concentration (0.1 M) (Sakakibara et al., 1996).

Nowadays, lactose-hydrolyzed dairy products have a remarkable importance since the deficiency at various levels of lactase (hypolactasia) affects nearly $70 \%$ of the world's population (Lomer et al., 2008). For this reason, milk lactose hydrolysis with $\beta$-galactosidase and US has been extensively studied (Sener et al., 2006; Demirhan and Özbek, 2009).

Sener et al. (2006) reported the simultaneous use of $\beta$-galactosidase from Kluyveromyces marxianus and ultrasonication for lactose hydrolysis in milk, obtaining a hydrolysis degree of $90 \%$ and a residual enzyme activity of $75 \%$ at the optimum operational conditions $\left(20 \mathrm{~W}\right.$, duty cycle $10 \%, 30 \mathrm{~min}, 1 \mathrm{mLL}^{-1}$ enzyme concentration). The time of exposure to US and the duty cycle were critical for hydrolysis as 
well as for enzyme stability. The residual lactose concentration and residual enzyme activity decreased when the effective time increased for all acoustic powers applied $(20-100 \mathrm{~W})$. With respect to US power, the residual lactose concentration increased with acoustic power. This decrease in the reaction rate can be explained by enzyme inactivation due to the shear forces generated in the sonified fluid. The reaction volume also had an effect on the enzyme activity: the residual lactose concentration decreased up to $250 \mathrm{~mL}$, whereas it began to increase above this value. The higher US energy per reaction volume for small reaction volumes, and the lower mass transfer rate for larger volumes, could support the results obtained in that paper. Almost identical conclusions were obtained in a study by Demirhan and Özbek (2009) on whey hydrolysis.

17.4.2.2 Enzymatic Synthesis of Carbohydrate Derivatives As previously mentioned, US is an environmentally green technology that has found a wide field of application in organic chemistry. It has been reported that the use of US may accelerate enzymatic synthesis in organic solvents with small amounts of added water to generate two-phase systems, and in viscous reaction media such as ionic liquids (IL) (Kwiatkowska et al.,2011; Chatel et al.,2014). In these media, US irradiation enhances enzyme activity by increasing the mass transfer rate of the substrate to the enzyme active site by means of cavitation, mechanical forces, and thermal effects, as well as the release rate of product from enzyme.

In the last few years, US have been extensively used in the production of esters. Among other properties of interest for the pharmaceutical, cosmetics, and food industries, these compounds can be used as bio-surfactants (Lerin et al., 2014). Furthermore, they are often used as emulsifying agents to improve food quality, as their hydrophilic-lipophilic balance can be easily adjusted by varying the number of hydroxyl groups from sugars (e.g., sucrose) substituted with different fatty acid chains. Esterification reactions often require long times $(\geq 24 \mathrm{~h})$ and US treatment noticeably contributes to overcoming this drawback (Shi et al., 2011).

An interesting research project on the US-accelerated enzymatic synthesis of sugar esters in pyridine was carried out by Xiao et al. (2005). They observed that the pretreatment of enzymes under suitable US conditions $\left(20 \mathrm{kHz}, 50^{\circ} \mathrm{C}, 50-120 \mathrm{~W}, 1-8 \mathrm{~h}\right)$ can improve their catalytic performance. The results showed that high US power $(120 \mathrm{~W})$ gave rise to better enzymatic synthesis of sugar esters. A $98 \%$ conversion of glucose could be obtained after $2 \mathrm{~h}$, whereas only $48 \%$ was observed in shaking under the same conditions.

The IL/enzyme/US combination may be an efficient approach for enzymatic synthesis of polysaccharide esters. Although ILs have been shown to be good reaction media for biocatalysis, the rate limitation is often caused by the low mass transfer rate due to the viscosity of these solvents. This can be overcome by using US (Chatel et al., 2014). In lipase-catalyzed esterification of glucose with lauric acid, enzymatic activity of Novozyme 435 immobilized on acrylic resin was highly enhanced by using supersaturated solutions under US irradiation (Lee et al.,2008). In this study, US irradiation $(47 \mathrm{kHz}, 185 \mathrm{~W})$ increased the dissolution rate of glucose in 1-butyl-3-methylimidazolium trifluoromethane sulfonate ([BMIM][TfO]) as compared to magnetic stirring (from 16 to $29 \mathrm{mMh}^{-1}$ ). The enzyme activity in the direct esterification was also increased about 4.7 times by using supersaturated glucose solutions under US irradiation. Furthermore, the stability of the enzyme in ILs with irradiation after being reused four times was similar to that without US. The same research group (Ha et al., 2010) 
carried out the esterification of fructose with palmitate in IL under US $(47 \mathrm{kHz}, 185 \mathrm{~W}$, $60^{\circ} \mathrm{C}, 6 \mathrm{~h}$ ) and the conversion was $78 \%$, while the use of magnetic stirring only led to $62 \%$ esterification.

Chen et al. (2008) studied the effect of US on enzymatic acylation of konjac glucomannan (KGM) with vinyl esters in tert-butanol. The acylated forms of KGM have shown to be promising as a novel drug, an environmentally benign emulsifier, and as drug carriers. The application of US irradiation $(20 \mathrm{kHz}, 100 \mathrm{~W}, 10 \mathrm{~s}$ on $/ 5 \mathrm{~s}$ off, $0.48 \mathrm{~W} \mathrm{~mL}^{-1}, 45^{\circ} \mathrm{C}, 24 \mathrm{~h}$ ) rather than shaking during acylation led to the improvement in the initial reaction rate, yield, and DS of the modified KGM. The effect of US on Novozym 435-catalyzed acylation decreased with an increase in the chain length of the acyl donors from $\mathrm{C}_{2}$ to $\mathrm{C}_{18}$. Further increase in power output up to $120 \mathrm{~W}$, however, resulted in a decrease in the reaction rate and DS of the product, suggesting partial inactivation of the enzyme.

Lily (Lilium lancifolium) polysaccharide has been acylated with immobilized Burkholderia cepacia lipase over vinyl acetate in the IL 1-butyl-3-methylimidazolium tetrafluoroborate ([BMIM][BF4]) (Wang et al., 2013). The application of US irradiation (30-180W, pulsed mode $10 \mathrm{~s}$ on $/ 5 \mathrm{~s}$ off) during acylation gave enhanced DS of the product up to $120 \mathrm{~W}$, and the rate was higher than with magnetic stirring during the first $9 \mathrm{~h}$. Moreover, $56 \%$ of enzymatic activity was maintained after eight reuses in batch under US irradiation.

In general, in these reactions US did not change the regioselectivity of the enzymatic acylation (Xiao et al., 2005; Chen et al., 2008).

Enzymatic isomerization of glucose into fructose has also been carried out in ILs assisted by US irradiation to improve the activity of immobilized glucose isomerase (IGI) obtained from Streptomyces murinus (Wang et al., 2012). Under the optimal US reaction conditions $(40 \mathrm{kHz}, 350 \mathrm{~W}), 45.3 \%$ yield of fructose was achieved in $10 \mathrm{~h}$ in 1-butyl-3-methylimidazolium chloride ([BMIM] [Cl], 3\% v/v), compared to $41.5 \%$ yield under stirring in [BMIM][Cl], 44.2\% under US without [BMIM] $[\mathrm{Cl}]$, and 38.9\% under stirring without [BMIM] [Cl] in $12 \mathrm{~h}$. The effect of IL was also important to the reusability of enzyme. Only a slight decrease $(5 \%)$ in enzymatic activity under US in $[\mathrm{BMIM}][\mathrm{Cl}]$ was observed after five uses, while $17 \%$ residual enzyme activity remained under stirring without IL.

17.4.2.3 Fermentation The effects of US on microbial fermentations could be attributed to the transient alteration of cell membrane permeability on US treatment, which promotes the mass transfer of substrates and the secretion of metabolites such as intracellular enzymes (Sakakibara et al., 1996). Moreover, during sonication cell viability could decrease when the membrane disruption is significant and could even destroy the cells' reproductive capability, depending on the injury to the wall and membrane (Sakakibara et al., 1996; Yeo and Liong, 2011).

In food science and technology, US stimulation of enzymes and bacteria can be used to obtain fermented milks. Although lactose-hydrolyzed yoghurts have usually been produced by fermentation of lactose-hydrolyzed milk or by the simultaneous addition of $\beta$-galactosidase and lactic acid bacteria, they can also be prepared by sonication during the course of fermentation (Toba et al., 1990; Wang et al., 1996; Wang and Sakakibara, 1997).

Toba et al. (1990) inoculated milk with Lactobacillus delbrueckii or L. helveticus, followed by incubation for $4 \mathrm{~h}$, sonication $\left(20 \mathrm{kHz}, 60 \mathrm{~W}, 20 \mathrm{~min}, 0^{\circ} \mathrm{C}\right)$, and additional incubation for $12 \mathrm{~h}$. Sonication resulted in $71-74 \%$ depletion in the initial lactose, 
whereas only $39-51 \%$ lactose hydrolysis was reached in non-sonicated milk. Sakakibara et al. (1994), Wang et al. (1996), and Wang and Sakakibara (1997) also examined the effect of US irradiation on milk fermentation, using a bioreactor $\left(200 \mathrm{kHz}, 17.2 \mathrm{~kW} \mathrm{~m}^{-2}\right)$. In general, the hydrolysis of lactose in milk increased by applying US but the cell viability decreased. However, the viable cell count increased again when the US was stopped because US did not destroy the ability for cell propagation. A higher degree of lactose hydrolysis (71\%) and higher cell viabilities $\left(10^{9} \mathrm{cfu} \mathrm{cm}^{-3}\right)$ were achieved with the combination of $\mathrm{pH}$ control at 6.5, sonicated fermentation for $2 \mathrm{~h}$, and further static incubation for $16 \mathrm{~h}$ (Wang et al., 1996). On the other hand, the released $\beta$-galactosidase hydrolyzes lactose into glucose and galactose, which are more readily utilized by lactic bacteria, thereby reducing production time, improving the acidifying activity of lactobacilli, and enhancing the sweet taste without increasing the caloric content.

During the last few years US has been used as a potential alternative to conventional processing to obtain good quality symbiotic fermented milks without adding prebiotics and $\beta$-galactosidase. The products are low in lactose, high in galactooligosaccharides (GOS), and have less undesirable flavor from acetic and propionic acids (Nguyen et al., 2009, 2012).

Nguyen et al. (2009) studied the fermentative activities of bifidobacteria in milk stimulated by high-intensity US (20 kHz, $100 \mathrm{~W}, 7-30 \mathrm{~min})$. Results showed that US under selected conditions could reduce the fermentation time required to reach $\mathrm{pH} 4.7$ for samples with strains of Bifidobacterium infantis and B. breve. Later, Nguyen et al. (2012) reported the effect of high-intensity US on the carbohydrate metabolism of bifidobacteria in milk fermentation. US applied in the same conditions accelerated lactose hydrolysis and the transgalactosylation reaction in all fermented milks throughout $24 \mathrm{~h}$ of incubation. During the early stages of fermentation, an increase in glucose and galactose release, as well as of GOS, was produced, stimulating the growth of the bifidobacteria immediately after US treatment (Nguyen et al., 2009). This fact gave rise to major production of organic acids in the later stage of milk fermentation (Nguyen et al.,2012) and reduced the ratio of acetic to lactic acids in milk fermented by bifidobacteria, enhancing the taste of fermented milk. Other effects of US treatment were an increase in the water-holding capacity of the yoghurt, a reduction in the syneresis, and an improvement in texture.

US treatments have been widely used in fermentative processes aimed at producing biomass or particular metabolites of interest. Zhang et al. (2014) reported a US process to enhance the production of polysaccharides from mycelial fermentation of Phellinus igniarius. In these assays, a flat plate US reactor operating under optimized conditions $(68 \mathrm{kHz}, 600 \mathrm{~W}, 65 \mathrm{~min}$, pulsed $25 \mathrm{~s}$ on $/ 5 \mathrm{~s}$ off, culture time 3.8 days at $26^{\circ} \mathrm{C}$ ) produced a $22.6 \%$ of yield increase compared with the control without US. The monomeric composition of polysaccharides, comprising D-glucose, L-rhamnose and D-mannose, quantitatively changed since the samples pre-treated with US had molar ratios 11:14:1, and without US of 9:3:1, respectively. These results indicated that US treatment could not only accelerate mycelium growth, but also promote the secondary metabolite biosynthesis. However, under long exposure to US, the mycelium might be damaged to some extent, which results in hindering the fermentation process. Sonication appeared to influence primary and secondary growth metabolism differently depending on the conditions (Kwiatkowska et al., 2011). 
US-assisted fermentation by the yeast $K$. marxianus (ATCC 46537) also enhances bioethanol production from lactose under batch conditions, and using a $7.5 \mathrm{~L}$ ( $3 \mathrm{~L}$ working volume) stirred bioreactor with a sonotrode mounted in an external chamber and continuous recirculation in the bioreactor at $0.2 \mathrm{~L} \mathrm{~min}^{-1}$ flow rate. At optimal conditions $\left(11.8 \mathrm{~W} \mathrm{~cm}^{-2}, 20 \%\right.$ duty cycle) the extracellular and intracellular levels of $\beta$-galactosidase enhanced and the final ethanol concentration was $5.2 \mathrm{~g} \mathrm{~L}^{-1}$ (nearly 3.5-fold that of the control fermentation). However, a 40\% duty cycle showed an adverse impact on cell growth (Sulaiman et al., 2011).

Another interesting process involving US is the production of bulk chemicals from biomass. Sugarcane bagasse hydrolysate pre-treated for $40 \mathrm{~min}$ at $150 \mathrm{~W}$ is used as the carbon and nitrogen source to achieve the green and economical production of succinic acid with a $79 \%$ yield and productivity of $0.99 \mathrm{~g} \mathrm{~L}^{-1} \mathrm{~h}^{-1}$ (an improvement of $20 \%$ over the control method) (Xi et al.,2013).

Oral administration of hyaluronic acid has been reported to improve skin health, and US treatment has been used to enhance its production by lactobacilli. Thus, ultrasonication $\left(30 \mathrm{kHz}, 115 \mathrm{~W} \mathrm{~cm}^{-2}\right.$, tip $\left.3 \mathrm{~mm}, 1-3 \mathrm{~min}, 25^{\circ} \mathrm{C}\right)$ increased the hyaluronic acid content up to $51.6 \%$ with respect to the control (Hor et al., 2014). These data demonstrated that a sub-lethal physical treatment such as ultrasonication can be applied to increase the membrane permeability of lactobacilli cells and subsequently increase the release of bioactive metabolites.

\subsection{Conclusions and Future Trends}

Although the application of US in the carbohydrate field has been known for several decades, according to the literature presented in this chapter, the use of US for several processes and reactions involving carbohydrates is gaining wide interest within the food science and technology field.

US offers net advantages in terms of productivity, yield, and selectivity, with better processing time and reduced chemical and physical hazards. In the US processes studied, it is important to consider both the sonophysical and sonochemical effects, associated with the use of different ranges of frequency and power, to enhance the production and the quality of the resulting products. To date, depolymerization of polysaccharides and sonocrystallization are probably the most studied US applications and the most feasible processes to be applied on an industrial scale. However, the successful implementation of US to obtain molecules with specific and, in some cases, improved functionality (technological and biological) has also contributed to extending its use in different applications. Particularly attractive is the use of US in biotechnological processes in which small variations in the conditions can activate or inactivate the enzymes involved in carbohydrate reactions. It is assumed that interest in this technology will continue to increase in the coming decades due to it being a green technology, and because of its easy manipulation, affordability, and the development of new transductors/equipment, which will broaden the possibilities for use. In spite of the fact that considerable attention has been paid to optimizing the conditions leading to the best processes, it is still necessary to continue this research in order to obtain reproducible results as a step prior to the scale-up of the technology. Moreover, the use of US treatments as a way to intensifying other processes in terms of yield and velocity, and to have tools available that enable new structures to be derived from carbohydrates with specific and/or improved properties has also generally been accepted. 


\section{Acknowledgements}

This work has been supported by projects AGL2011-27884 from MICINN and AGL2014-53445-R from MINECO, by the Comunidad Autónoma of Madrid and European funding from FEDER program (project S2013/ABI-3028, AVANSECAL), and by Fundación Ramón Areces. A.C.S. thanks MINECO of Spain for a Ramón y Cajal contract.

\section{References}

Barton, S., Bullock, C., and Weir, D. (1996) The effects of ultrasound on the activities of some glycosidase enzymes of industrial importance. Enzyme and Microbial Technology 18, 190-194.

Bashari, M., Eibaid, A., Wang, J.P., Tian, Y.Q., Xu, X.M., and Jin, Z.Y. (2013) Influence of low ultrasound intensity on the degradation of dextran catalyzed by dextranase. Ultrasonics Sonochemistry 20,155-161.

Bashari, M., Abdelhai, M.H., Abbas, S., Eibaid, A., Xu, X.M., and Jin, Z.Y. (2014) Effect of ultrasound and high hydrostatic pressure (US/HHP) on the degradation of dextran catalyzed by dextranase. Ultrasonics Sonochemistry 21, 76-83.

Benazzi, T., Calgaroto, S., Astolfi, V., Dalla Rosa, C., Oliveira, J.V., and Mazutti, M.A. (2013) Pretreatment of sugarcane bagasse using supercritical carbon dioxide combined with ultrasound to improve the enzymatic hydrolysis. Enzyme and Microbial Technology 52, 247-250.

Bhaskaracharya, R.K., Kentish, S., and Ashokkumar, M. (2009) Selected applications of ultrasonics in food processing. Food Engineering Reviews 1, 31-49.

Brochette, S., Descotes, G., Bouchu, A., Queneau, Y., Monnier, N., and Pétrier, C. (1997) Effect of ultrasound on KSF/O mediated glycosylations. Journal of Molecular Catalysis A: Chemical 123, 123-130.

Brochette-Lemoine, S., Trombotto, S., Joannard, D., Descotes, G., Bouchu, A., and Queneau, Y. (2000) Ultrasound in carbohydrate chemistry: sonophysical glucose oligomerisation and sonocatalysed sucrose oxidation. Ultrasonics Sonochemistry 7, 157-161.

Bund, R.K. and Pandit, A.B. (2007) Rapid lactose recovery from paneer whey using sonocrystallization: a process optimization. Chemical Engineering and Processing 46, 846-850.

Camino, N.A., Pérez, O.E., and Pilosof, A.M.R. (2009) Molecular and functional modification of hydroxypropylmethylcellulose by high-intensity ultrasound. Food Hydrocolloids 23, 1089-1095.

Chatel, G., de Oliveira Vigier, K., and Jérôme, F. (2014) Sonochemistry: What potential for conversion of lignocellulosic biomass into platform chemicals? ChemSusChem $\mathbf{7}$, 2774-2787.

Chemat, F., Huma, Z-E., and Khan, M.K. (2011) Applications of ultrasound in food technology: Processing, preservation and extraction. Ultrasonics Sonochemistry 18, 813-835.

Chen, X., Siu, K-C., Cheung, Y-C., and Wu, J-Y. (2014) Structure and properties of a $(1 \rightarrow 3)$ - $\beta$-D-glucan from ultrasound-degraded exopolysaccharides of a medicinal fungus. Carbohydrate Polymers 106, 270-275.

Chen, Z.G., Zong, M.H., Gu, Z.X., and Han, Y.B. (2008) Effect of ultrasound on enzymatic acylation of konjac glucomannan. Bioprocess and Biosystems Engineering 31, 351-356. 
Chow, R., Blindt, R., Kamp, A., Grocutt, P., and Chivers, R (2004) The microscopic visualization of the sonocrystallisation of ice using a novel ultrasonic cold stage. Ultrasonics Sonochemistry 11, 245-250.

Chow, R., Blindt, R., Chivers, R., and Povey, M. (2005) A study on the primary and secondary nucleation of ice by power ultrasound. Ultrasonics $\mathbf{4 3}, 227-230$.

Č́žzová, A., Bystrický, P., and Bystrický, S. (2015) Ultrasonic and free-radical degradation of mannan from Candida albicans. International Journal of Biological Macromolecules 75, 32-36.

Corzo-Martínez, M., Montilla, A., Megías-Pérez, R., Olano, A., Moreno, F.J., and Villamiel, M. (2014) Impact of high-intensity ultrasound on the formation of lactulose and Maillard reaction glycoconjugates. Food Chemistry 157, 186-192.

Czechowska-Biskup, R., Rokita, B., Lotfy, S., Ulanski, P., and Rosiak, J.M. (2005a) Degradation of chitosan and starch by $360-\mathrm{kHz}$ ultrasound. Carbohydrate Polymers $\mathbf{6 0}$, 175-184.

Czechowska-Biskup, R., Rokita, B., Ulanski, P., and Rosiak, J.M. (2005b) Radiationinduced and sonochemical degradation of chitosan as a way to increase its fat-binding capacity. Nuclear Instruments and Methods in Physics Research B 236, 383-390.

de Campos, A., Correa, A.C., Cannella, D., Teixeira, E.D., Marconcini, J.M., Dufresne, A., Mattoso, L.H.C., Cassland, P., and Sanadi, A.R (2013) Obtaining nanofibers from curauá and sugarcane bagasse fibers using enzymatic hydrolysis followed by sonication. Cellulose 20, 1491-1500.

Demirhan, E. and Özbek, B. (2009) A modeling study on hydrolysis of lactose recovered from whey and $\beta$-galactosidase stability under sonic treatment. Chemical Engineering Communications 196, 767-787.

Deora, N.S., Misra, N.N., Deswal, A., Mishra, H.N., Cullen, P.J., and Tiwari, B.K. (2013) Ultrasound for improved crystallization in food processing. Food Engineering Reviews 5, 36-44.

Gogate, P.R. and Kabadi, A.M. (2009) A review of applications of cavitation in biochemical engineering/biotechnology. Biochemical Engineering Journal 44, 60-72.

Gonçalves, P.M., Noreña, C.P.Z., da Silveira, N.P., and Brandelli, A. (2014) Characterization of starch nanoparticles obtained from Araucaria angustifolia seeds by acid hydrolysis and ultrasound. LWT-Food Science and Technology 58, 21-27.

Grönroos, A., Pirkonen, P., and Rupper, O. (2004) Ultrasonic depolymerisation of aqueous carboxymethylcellulose. Ultrasonics Sonochemistry 11, 9-12.

Guo, X., Ye, X., Sun, Y., Wu, D., Wu, N., Hu, Y., and Chen, S. (2014) Ultrasound effects on the degradation kinetics, structure, and antioxidant activity of sea cucumber fucoidan. Journal of Agricultural and Food Chemistry 62, 1088-1095.

Ha, S.H., Hiep, N.M., and Koo, Y.M. (2010) enhanced production of fructose palmitate by lipase-catalyzed esterification in ionic liquids. Biotechnology and Bioprocess Engineering 15, 126-130.

Hartel, R.W. (2013) Advances in Food Crystallization. Annual Review of Food Science and Technology 4, 277-292.

Hernoux-Villière, A., Lassi, U., and Lévêque, J.M. (2013) An original ultrasonic reaction with dual coaxial frequencies for biomass processing. Ultrasonics Sonochemistry 20, 1341-1344.

Hernoux, A., Lévêque, J.M., Lassi, U., Molina-Boisseau, S., and Marais, M.F. (2013) Conversion of a non-water soluble potato starch waste into reducing sugars under nonconventional technologies. Carbohydrate Polymers 92, 2065-2074.

Hor, K.C., Lew, L.C., Choi, S.B., and Liong, M.T. (2014) Effects of ultrasonication on the production of hyaluronic acid by lactobacilli. Acta Alimentaria 43, 324-332.

Hosseini, S.M.H., Emam-Djomeh, Z., Razavi, S.H., Moosavi-Movahedi, A.A., Saboury, A.A., Atri, M.S., and Van der Meeren, P. (2013) $\beta$-Lactoglobulin-sodium alginate 
interaction as affected by polysaccharide depolymerization using high intensity ultrasound. Food Hydrocolloids 32, 235-244.

Hu, A., Zheng, J., and Qiu, T. (2006) Industrial experiments for the application of ultrasound on scale control in the Chinese sugar industry. Ultrasonics Sonochemistry 13, 329-333.

Hu, A.J., Lu, J., Zheng, J., Sun, J.Y., Yang, L., Zhang, X.Q., Zhang, Y., and Lin, Q. (2013) Ultrasonically aided enzymatical effects on the properties and structure of mung bean starch. Innovative Food Science and Emerging Technologies 20, 146-151.

Jeon, Y.J., Park, P.J., and Kim, S.K. (2001) Antimicrobial effect of chitooligosaccharides produced by bioreactor. Carbohydrate Polymers 44, 71-76.

Karaman, S., Yilmaz, M.T., Ertugay, M.F., Baslar, M., and Kayacier, A. (2012) Effect of ultrasound on steady and dynamic shear properties of glucomannan based salep dispersions: Optimization of amplitude level, sonication time and temperature using response surface methodology. Ultrasonics Sonochemistry 19, 928-938.

Kardos, N. and Luche, J.L. (2001) Sonochemistry of carbohydrate compounds. Carbohydrate Research 332,115-131.

Kassai, M.R., Arul, J., and Charlet, G. (2008) Fragmentation of chitosan by ultrasonic irradiation. Ultrasonics Sonochemistry 15, 1001-1008.

Khanal, S.K., Montalbo, M., van Leeuwen, J., Srinivasan, G., and Grewell, D. (2007) Ultrasound enhanced glucose release from corn in ethanol plants. Biotechnology and Bioengineering 98, 978-985.

Kim, J.Y., Park, D.J., and Lim, S.T. (2008) Fragmentation of waxy rice starch granules by enzymatic hydrolysis. Cereal Chemistry 85, 182-187.

Kwiatkowska, B., Bennett, J., Akunna, J., Walker, G.M., and Bremner, D.H. (2011) Stimulation of bioprocesses by ultrasound. Biotechnology Advances 29, 768-780.

Leaes, E.X., Zimmermann, E., Souza, M., Ramon, A.P., Mezadri, E.T., Dal Pra, V., Terra, L.M., and Mazutti, M.A. (2013) Ultrasound-assisted enzymatic hydrolysis of cassava waste to obtain fermentable sugars. Biosystems Engineering 115, 1-6.

Lee, S.H., Nguyen, H.M., Koo, Y.M., and Ha, S.H. (2008) Ultrasound-enhanced lipase activity in the synthesis of sugar ester using ionic liquids. Process Biochemistry 43, 1009-1012.

Lerin, L.A., Loss, R.A., Remonatto, D., Zenevicz, M.C., Balen, M., Netto, V.O., Ninow, J.L., Trentin, C.M., Oliveira, J.V., and de Oliveira, D. (2014) A review on lipase-catalyzed reactions in ultrasound-assisted systems. Bioprocess and Biosystems Engineering 37, 2381-2394.

Li, C.Z., Yoshimoto, M., Ogata, H., Tsukuda, N., Fukunaga, K., and Nakao, K. (2005) Effects of ultrasonic intensity and reactor scale on kinetics of enzymatic saccharification of various waste papers in continuously irradiated stirred tanks. Ultrasonics Sonochemistry 12, 373-384.

Li, R.S. and Feke, D.L. (2015) Rheological and kinetic study of the ultrasonic degradation of xanthan gum in aqueous solutions. Food Chemistry 172, 808-813.

Liu, H., Bao, J., Du, Y., Zhou, X., and Kennedy, J.F. (2006) Effect of ultrasonic treatment on the biochemphysical properties of chitosan. Carbohydrate Polymers 64, 553-559.

Lomer, M.C.E., Parkes, G.C., and Sanderson, J.D. (2008) Review article: lactose intolerance in clinical practice - myths and realities. Alimentary, Pharmacology and Therapeutics 27, 93-103.

Lu, Y., Yan, R., Ma, X., and Wang, Y. (2013) Synthesis and characterization of raffinose fatty acid monoesters under ultrasonic irradiation. European Food Research and Technology 237, 237-244.

Luo, Z.G., Fu, X., He, X.W., Luo, F.X., Gao, Q.Y., and Yu, S.J. (2008) Effect of ultrasonic treatment on the physicochemical properties of maize starches differing in amylose content. Starch 60, 646-653. 
Mason, T.J., Paniwnyk, L., and Lorimer, J.P. (1996) The uses of ultrasound in food technology. Ultrasonics Sonochemistry 3, S253-S260.

Mason, T.J. and Lorimer, J.P. (2002) General Principles. In Applied Sonochemistry: Uses of power ultrasound in chemistry and processing (eds T.J. Mason and J.P. Lorimer), pp. 25-74, Wiley, New York.

Miao, W.H., Xu, X.Y. Zhou, B., Pan, S.Y., Wang, K.Q., Fan, C.H., and Wang, L.F. (2014) Improvement of sugar production from potato pulp with microwave radiation and ultrasonic wave pretreatments. Journal of Food Process Engineering 37, 86-90.

Montalbo-Lomboy, M., Johnson, L., Khanal, S.K., van Leeuwen, J.H., and Grewell, D. (2010) Sonication of sugary-2 corn: A potential pretreatment to enhance sugar release. Bioresource Technology 101, 351-358.

Nguyen, T.M.P., Lee, Y.K., and Zhou, W.B. (2009) Stimulating fermentative activities of bifidobacteria in milk by high intensity ultrasound. International Dairy Journal 19, 410-416.

Nguyen, T.M.P., Lee, Y.K., and Zhou, W.B. (2012) Effect of high intensity ultrasound on carbohydrate metabolism of bifidobacteria in milk fermentation. Food Chemistry 130, 866-874.

Nguyen, V.P.T., Le, T.T., and Le, V.V.M. (2013) Application of combined ultrasound and cellulase preparation to guava (Psidium guajava) mash treatment in juice processing: optimization of biocatalytic conditions by response surface methodology. International Food Research Journal 20, 377-381.

Nikolic, S., Mojovic, L., Rakin, M., Pejin, D., and Pejin, J. (2010) Ultrasound-assisted production of bioethanol by simultaneous saccharification and fermentation of corn meal. Food Chemistry 122, 216-222.

No, H.K., Park, N.Y., Lee, S.H., and Meyers, S.P. (2002) Antibacterial activity of chitosans and chitosan oligomers with different molecular weights. International Journal of Food Microbiology 74, 65-72.

Özbek, B. and Ülgen, K.O. (2000) The stability of enzymes after sonication. Process Biochemistry 35, 1037-1043.

Panchev, I.N., Kirtchev, N.A., and Kratchanov, C.G. (1994) On the production of low esterified pectins by acid maceration of pectic raw materials with ultrasound treatment. Food Hydrocolloids 8, 9-17.

Portenlänger, G. and Heusinger, H. (1997) The influence of frequency on the mechanical and radical effects for the ultrasonic degradation of dextrans. Ultrasonics Sonochemistry 4, 127-130.

Prajapat, A.L. and Gogate, P.R. (2015) Depolymerization of guar gum solution using different approaches based on ultrasound and microwave irradiations. Chemical Engineering and Processing 88,1-9.

Rhoades, J. and Roller, S. (2000) Antimicrobial actions of degraded and native chitosan against spoilage organisms and laboratory media and foods. Applied and Environmental Microbiology 66, 80-86.

Rokhina, E.V., Lens, P., and Virkutyte, J. (2009) Low-frequency ultrasound in biotechnology: State of the art. Trends in Biotechnology 27, 298-306.

Ruecroft, G., Hipkiss, D.L., Ly, T., Maxted, N., and Cains, P.W. (2005) Sonocrystallization: the use of ultrasound for improved industrial crystallization. Organic Process Research and Development 9, 923-932.

Sakakibara, M., Wang, D.Z., Ikeda, K., and Suzuki, K. (1994) Effect of ultrasonic irradiation on production of fermented milk with Lactobacillus delbrueckii. Ultrasonics Sonochemistry 1, 107-110.

Sakakibara, M., Wang, D., Takahashi, R., Takahashi, K., and Mori, S. (1996) Influence of ultrasound irradiation on hydrolysis of sucrose catalyzed by invertase. Enzyme and Microbial Technology 18, 444-448. 
Schmid, G. and Rommel, O. (1939) Rupture of macromolecules with ultrasound. Journal of Physical Chemistry A 185, 97-139.

Sener, N., Apar, D.K., and Özbek, B. (2006) A modeling study on milk lactose hydrolysis and $\beta$-galactosidase stability under sonication. Process Biochemistry 41, 1493-1500.

Seshadri, R., Weiss, J., Hulbert, G.J., and Mount, J. (2003) Ultrasonic processing influences rheological and optical properties of high-methoxyl pectin dispersions. Food Hydrocolloids 17, 191-197.

Shewale, S.D. and Pandit, A.B. (2009) Enzymatic production of glucose from different qualities of grain sorghum and application of ultrasound to enhance the yield. Carbohydrate Research 344, 52-60.

Shi, Y.G., Li, J.R., and Chu, Y.H. (2011) Enzyme-catalyzed regioselective synthesis of sucrose-based esters. Journal of Chemical Technology and Biotechnology 86, 1457-1468.

Stasiak, D.M. and Dolatowski, Z.J. (2008) Efficiency of sucrose crystallization from sugar beet magma after sonication. Polish Journal of Natural Science. 23, 521-530.

Subhedar, P.B. and Gogate, P.R. (2013) Intensification of enzymatic hydrolysis of lignocellulose using ultrasound for efficient bioethanol production: A review. Industrial and Engineering Chemistry Research 52,11816-11828.

Sulaiman, A.Z., Ajit, A., Yunus, R.M., and Chisti, Y. (2011) Ultrasound-assisted fermentation enhances bioethanol productivity. Biochemical Engineering Journal 54, 141-150.

Szabo, O.E. and Csiszar, E. (2013) The effect of low-frequency ultrasound on the activity and efficiency of a commercial cellulase enzyme. Carbohydrate Polymers 98, 1483-1489.

Tiwari, B.K., Muthukumarappan, K., O'Donell, C.P., and Cullen, P.J. (2014) Rheological properties of sonicated guar, xanthan and pectin dispersions. International Journal of Food Properties 13, 223-233.

Toba, T., Hayasaka, I., Taguchi, S., and Adachi, S. (1990) A new method for manufacture of lactose-hydrolyzed fermented milk. Journal of the Science of Food and Agriculture 52, 403-407.

Venegas-Sánchez, J.A., Motohiro, T., and Takaomi, K. (2013) Ultrasound effect used as external stimulus for viscosity change of aqueous carrageenans. Ultrasonics Sonochemistry 20,1081-1091.

Wang, D.Z., Sakakibara, M., Kondoh, N., and Suzuki, K. (1996) Ultrasound-enhanced lactose hydrolysis in milk fermentation with Lactobacillus bulgaricus. Journal of Chemical Technology and Biotechnology 65, 86-92.

Wang, D. and Sakakibara, M. (1997) Lactose hydrolysis and $\beta$-galactosidase activity in sonicated fermentation with Lactobacillus strains. Ultrasonics Sonochemistry 4, 255-261.

Wang, F., Chen, Z.G., and Zhu, H.J. (2013) An efficient enzymatic modification of lily polysaccharide in ionic liquid under ultrasonic irradiation. Biochemical Engineering Journal 79, 25-28.

Wang, J., Jin, X., and Chang, D. (2009) Chemical modification of chitosan under highintensity ultrasound and properties of chitosan derivatives. Carbohydrate Polymers $\mathbf{7 8}$, 175-177.

Wang, Y., Pan, Y., Zhang, Z.Q., Sun, R.X., Fang, X.X., and Yu, D.H. (2012) Combination use of ultrasound irradiation and ionic liquid in enzymatic isomerization of glucose to fructose. Process Biochemistry 47, 976-982.

Wu, T., Zivanovic, S., Hayes, D., and Weiss, J. (2008) Efficient reduction of chitosan molecular weight by high intensity ultrasound: underlying mechanism and effect on process parameters. Journal of Agricultural and Food Chemistry 56, 5112-5119.

Wu, Y., Du, X.F., Ge, H.H., and Lv, Z. (2011) Preparation of microporous starch by glucoamylase and ultrasound. Starch-Starke 63, 217-225. 
Xi, Y.L., Dai, W.Y., Xu, R., Zhang, J.H., Chen, K.Q., Jiang, M., Wei, P. and Ouyang, P.K. (2013) Ultrasonic pretreatment and acid hydrolysis of sugarcane bagasse for succinic acid production using Actinobacillus succinogenes. Bioprocess and Biosystems Engineering 36, 1779-1785.

Xiao, Y.M., Wu, Q., Cai, Y., and Lin, X.F. (2005) Ultrasound-accelerated enzymatic synthesis of sugar esters in nonaqueous solvents. Carbohydrate Research 340, 2097-2103.

Yachmenev, V., Condon, B., Klasson, T., and Lambert, A. (2009) Acceleration of the Enzymatic Hydrolysis of Corn Stover and Sugar Cane Bagasse Celluloses by Low Intensity Uniform Ultrasound. Journal of Biobased Materials and Bioenergy 3, 25-31.

Yang, H.Y., Wang, K., Song, X.L., and Xu, F. (2011) Production of xylooligosaccharides by xylanase from Pichia stipitis based on xylan preparation from triploid Populas tomentosa. Bioresource Technology 102, 7171-7176.

Yeo, S.K. and Liong, M.T. (2011) Effect of Ultrasound on the Growth of Probiotics and Bioconversion of Isoflavones in Prebiotic-Supplemented Soymilk. Journal of Agricultural and Food Chemistry 59, 885-897.

Yeo, S.K. and Liong, M.T. (2013) Effects and applications of sub-lethal ultrasound, electroporation and UV radiations in bioprocessing. Annals of Microbiology 63, 813-824.

Zhang, H., Ma, H., Liu, W., Pei, J., Wang, Z., Zhou, H., and Yan, J. (2014) Ultrasound enhanced production and antioxidant activity of polysaccharides from mycelial fermentation of Phellinus igniarius. Carbohydrate polymers 113, 380-387.

Zhang, L., Ye, X., Ding, T., Sun, X., Xu, Y., and Liu, D. (2013a) Ultrasound effects on the degradation kinetics, structure and rheological properties of apple pectin. Ultrasonics Sonochemistry 20, 222-231.

Zhang, L., Xingqian, Y., Xue, S.J., Zhang, X., Liu, D., Meng, R., and Chen, S. (2013b) Effect of high-intensity ultrasound on the physicochemical properties and nanostructure of citrus pectin. Journal of the Science of Food and Agriculture 93, 2028-2036.

Zheng, J., Li, Q., Hu, A., Yang, L., Lu, J., Zhang, X., and Lin, Q. (2013) Dual-frequency ultrasound effect on structure and properties of sweet potato starch. Starch $\mathbf{6 5}$, 621-627. 